\title{
Combined physiological, transcriptome, and cis-regulatory element analyses indicate that key aspects of ripening, metabolism, and transcriptional program in grapes (Vitis vinifera L.) are differentially modulated accordingly to fruit size
}

\author{
D. C. J. Wong ${ }^{1}$, R. Lopez Gutierrez ${ }^{1}$, N. Dimopoulos ${ }^{1}$, G. A. Gambetta ${ }^{2}$ and S. D. Castellarin ${ }^{\text {* }}$
}

\begin{abstract}
Background: In wine grape production, management practices have been adopted to optimize grape and wine quality attributes by producing, or screening for, berries of smaller size. Fruit size and composition are influenced by numerous factors that include both internal (e.g. berry hormone metabolism) and external (e.g. environment and cultural practices) factors. Combined physiological, biochemical, and transcriptome analyses were performed to improve our current understanding of metabolic and transcriptional pathways related to berry ripening and composition in berries of different sizes.

Results: The comparison of berry physiology between small and large berries throughout development (from 31 to 121 days after anthesis, DAA) revealed significant differences in firmness, the rate of softening, and sugar accumulation at specific developmental stages. Small berries had significantly higher skin to berry weight ratio, lower number of seeds per berry, and higher anthocyanin concentration compared to large berries. RNA-sequencing analyses of berry skins at 47,74, 103, and 121 DAA revealed a total of 3482 differentially expressed genes between small and large berries. Abscisic acid, auxin, and ethylene hormone pathway genes were differentially modulated between berry sizes. Fatty acid degradation and stilbenoid pathway genes were upregulated at 47 DAA while cell wall degrading and modification genes were downregulated at 74 DAA in small compared to large berries. In the late ripening stage, concerted upregulation of the general phenylpropanoid and stilbenoid pathway genes and downregulation of flavonoid pathway genes were observed in skins of small compared to large berries. Cis-regulatory element analysis of differentially expressed hormone, fruit texture, flavor, and aroma genes revealed an enrichment of specific regulatory motifs related to bZIP, bHLH, AP2/ERF, NAC, MYB, and MADS-box transcription factors.

Conclusions: The study demonstrates that physiological and compositional differences between berries of different sizes parallel transcriptome changes that involve fruit texture, flavor, and aroma pathways. These results suggest that, in addition to direct effects brought about by differences in size, key aspects involved in the regulation of ripening likely contribute to different quality profiles between small and large berries.
\end{abstract}

Keywords: Aroma, Cell wall, Flavonoid, Grapevine, Hormone, Promoter, Quality, RNA-seq, Secondary metabolism, Transcriptomics

\footnotetext{
* Correspondence: simone.castellarin@ubc.ca

${ }^{1}$ Wine Research Centre, University of British Columbia, Vancouver, BC, Canada

Full list of author information is available at the end of the article
} 


\section{Background}

Grapes (Vitis vinifera L.) are a highly valued horticultural crop with production covering approximately 7 million ha in 90 countries. The grape berry is extremely rich in secondary metabolites ranging from anthocyanins, carotenoids, norisoprenoids, tannins, terpenes, and other volatile organic compounds. These metabolites are very important to wine production as they affect wine quality by determining its color, aroma, and flavor [1]. Wine-grape growers adopt various vineyard management practices in order to optimize grape and wine quality attributes. Some of these practices involve producing (e.g. via applied water deficits) and/or selecting (e.g. via postharvest sorting) berries according to size with the belief that better wines are produced from small berries due to a higher skin to berry weight ratio. The reasoning being that this higher skin to berry weight ratio results in higher concentrations of key secondary metabolites accumulated in the skin $[2,3]$. These practices are becoming increasingly popular and machines are even sold to automatically sort berries based on size.

The grape berry is a non-climacteric fruit with a double-sigmoidal growth curve that can be separated into three major stages [4]. The first stage of development sees a rapid increase in berry size due to high rates of cell division and expansion in the berry pericarp. Coinciding with the rapid growth is the biosynthesis of phenolic compounds, such as tannins and hydroxycinnamates, and organic acids, such as tartaric and malic acid. In the second stage, the berry experiences a lag phase, where pericarp growth is arrested and the embryo completes its development. At the end of the second stage, the berry undergoes veraison (the onset of ripening) and enters the third and final stage. During this phase, the berry experiences a second period of rapid cell expansion as the pericarp grows to its final size. Many changes in berry metabolism occur: accumulation of sugars, decrease in organic acid concentration, and production of various secondary metabolites. Thus, berry size and composition will differ depending on the stage of development.

Hormones play central roles in berry ripening and as environmental mediators (reviewed in [5]). During the first phase of development, auxins are present at high levels, and then decrease to very low levels as the berry undergoes veraison $[6,7]$. Just prior to veraison, a small transient peak in ethylene is observed $[8,9]$ as well as sharp increases in abscisic acid (ABA) [10-13]. These observations indicate that $\mathrm{ABA}$ and ethylene are strong candidates as promoters of ripening. Treating berries with these hormones can affect the timing of veraison as well as other parameters, including fruit size and composition (reviewed in [5]). For example, treating berries with auxin prior to veraison temporarily delays berry growth, and sugar and anthocyanin accumulation [6].

Many factors influencing berry size are intrinsic, being related to the individual berry itself, such as seed number [14] and seed weight [15]. Recent evidence has shown that Pinot Noir and Cabernet Sauvignon seeded berries showed greater cell division and expansion than unseeded ones, resulting in larger berries [16]. Gouthu and Deluc [17] found a relationship between seed relative abundance and hormone content, where there were distinct differences in auxin and ABA levels between berries with different seed to berry weight ratios prior to veraison.

External factors, such as the environment and cultural practices, can also play a remarkable role in determining berry size. Water deficit $[18,19]$ and some pruning strategies [20] can result in smaller berries with higher phenolic content in the skin. However, other treatments may lower the concentration of some phenolics along with a reduction in berry size. This is seen with differences in the microclimate of clusters, where shading results in smaller berries with a lower phenolic content in the skin compared to light exposed clusters [21].

There are contrasting conclusions regarding differences in berry composition when comparing berries strictly on size. Some research indicates no differences between sizes [19, 22], while other research shows smaller Sauvignon Blanc berries having lower methoxypirazine concentrations (herbaceous aromatics accumulated in several cultivated varieties) compared to larger berries [23]. Similarly, there is no consensus on whether smaller berries make superior wines. Gil et al. [24] demonstrated that smaller grapes produced wines of deeper color and that size is inversely correlated with the concentration of phenolics, such as anthocyanins and stilbenes. In contrast, others have found that smaller berries do not translate into discernable differences in the resulting wines [22].

Changes in gene expression often parallel changes in berry skin metabolism throughout berry development $[12,25-28]$ and in response to stresses, such as water deficit [12, 29] and UV [30]. Many transcripts related to berry ripening and quality traits, such as those involved in hormone, phenylpropanoid, terpenoid, fatty acid, and cell wall metabolism, are modulated during development and in response to the environment. However, despite the strong impact on wine composition and quality, the regulation of transcripts/pathways related to ripening and berry composition in skins of differently sized berries is still unknown. In this study, our goal was to better understand the relationship between berry size, fruit ripening, and berry metabolism. We characterized how field grown Merlot berries differ in their ripening, metabolism, and transcriptional program in relation to 
berry size. We considered two extreme size classes and compared berry physiology, composition, and whole genome gene expression (RNA-sequencing) in the skin throughout development in order to determine the biological processes that discriminate between the two classes of berries.

\section{Methods}

\section{Sample collection and physiological measurements}

$V$. vinifera L.'Merlot' clone 181 vines were grown in a vineyard located in Oliver (British Columbia, Canada; $\left.49^{\circ} 13^{\prime} 18.8^{\prime \prime} \mathrm{N} 119^{\circ} 33^{\prime} 28.8^{\prime \prime} \mathrm{W}\right)$. Three biological replicates of fruit samples were harvested from three separate rows. Each replicate had 120 to 170 berries randomly collected from 30 vines per row at $31,39,47,51,54,57$, $60,64,67,74,103$, and 121 days after anthesis (DAA) in 2014. Care was taken to avoid physical damage as berries were trimmed off the cluster at the pedicel and placed into aluminized mylar zip-lock bags to prevent water and turgor loss [31]. The bags were then immediately placed into a cooling box at ambient temperature and transported to the laboratory. Berry diameter and elasticity (E), a precise quantification of berry firmness [13], were recorded for each berry [32] and berries were individually bagged, labeled, and stored at $-80{ }^{\circ} \mathrm{C}$ until the following analyses were conducted. From the population of berries at each sampling point, for each biological replicate seven berries were selected and pooled according to their size. Two pools were created: large berries, consisting of berries included in the top 90-95th percentile and small berries, consisting of berries included in the bottom 10-15th. These berries were used to calculate the evolution of E and total soluble solids (TSS), using a manual refractometer, across the season. Additional pools of seven berries selected from the same percentile at 47 (before ripening, $4.9^{\circ} \mathrm{Brix}$ ), 74 (early ripening, $17.5^{\circ} \mathrm{Brix}$ ), 103 (ripening, $22.4^{\circ} \mathrm{Brix}$ ) and 121 (late ripening, $25.3^{\circ} \mathrm{Brix}$ ) were used for both metabolite (see following paragraphs) and RNA-sequencing (RNA-seq) analyses. Three biological replicates for each treatment were considered for both metabolite and RNA-seq analysis.

\section{Liquid chromatography (LC) and LC-mass spectrophotometric (MS) analysis}

Berries were peeled while still frozen using a scalpel. Flesh tissue was then used for determining sugar and organic acid concentration, and skin tissue for anthocyanin content.

For the determination of sugar (glucose and fructose) and organic acid (malic and tartaric acid) content, flesh tissues were grounded to a fine powder and centrifuged at $16,000 \mathrm{~g}$ for $10 \mathrm{~min}$. Afterwards, the supernatant was passed through a $0.22 \mu \mathrm{m}$ PVDF $13 \mathrm{~mm}$ filter
(Whatman Inc., Sanford, USA) and measured via HPLC on an Agilent 1100 HPLC system with a refractive index detector (Agilent Technologies, USA). An aliquot of $20 \mu \mathrm{l}$ of extract was injected into a NUCLEOGEL ${ }^{\oplus}$ ION 300 OA column $(300 \mathrm{~mm} \times 7.8 \mathrm{~mm}$ ID, $10 \mu \mathrm{m})$ (Machery-Nagel Inc., USA), maintained at $71{ }^{\circ} \mathrm{C}$. The mobile phase was $2.5 \mathrm{mM} \mathrm{H}_{2} \mathrm{SO}_{4}$ with a flow rate of $0.55 \mathrm{ml} / \mathrm{min}$. Quantification of metabolite concentration (expressed as $\mathrm{mg} / \mathrm{ml}$ of juice) was based on calibration curves of authentic standards.

For the extraction of anthocyanins, $0.2 \mathrm{~g}$ of skins were grounded and extracted in $2 \mathrm{ml} 50 \%(v / v)$ methanol in water for $3 \mathrm{~h}$ with rigorous shaking. The supernatant was centrifuged, filtered and measured on an Agilent 1100 LC/MSD Trap XCT Plus mass spectrometer. Separation of anthocyanin compounds was achieved on an Agilent Zorbax SB-C18 column (150 mm $\times 4.6 \mathrm{~mm}$ ID, $1.8 \mu \mathrm{m})$ held at $57{ }^{\circ} \mathrm{C}$. The mobile phases used were: water-formic acid (2\%), solvent $\mathrm{A}$, and acetonitrileformic acid (2\%), solvent B. Flow rate was $0.8 \mathrm{ml} / \mathrm{min}$. The solvent gradient program was $0.5 \mathrm{~min}, 6 \% \mathrm{~B}$; 4 min, $10 \%$ B; 13 min, $25 \%$ B; 20 min, $35 \%$ B; 25 min, $60 \% \mathrm{~B} ; 30 \mathrm{~min}, 95 \% \mathrm{~B}$; and $32 \mathrm{~min}, 6 \% \mathrm{~B}$. The anthocyanins mass spectra were analyzed after electrospray ionization (ESI) in alternating positive and negative ionization mode with a scan range between 50 and $850 \mathrm{~m} / \mathrm{z}$. Quantification of single and total anthocyanins was based on malvidin 3-glucoside equivalents (expressed as $\mathrm{mg} / \mathrm{g}$ fresh weight of berry skin). The percentages of 3 ' 4'-OH, 3'4'5'-OH, and methoxylated anthocyanins were calculated among monoglucoside anthocyanins.

\section{RNA extraction, sequencing, and data analysis}

Extraction of total RNA was achieved with the Spectrum Plant Total RNA kit (Sigma-Aldrich) using $\sim 80 \mathrm{mg}$ of grounded skins according to the manufacturer's protocol. The integrity of the extracted RNA was determined on an Agilent 2100 Bioanalyzer (Agilent) ensuring a RIN score $>7.5$ prior to library construction. Ribosomal RNA depleted library construction was performed using an in-house workflow using customized kits from NEB at the Canada's Michael Smith Genome Sciences Center (Vancouver, Canada) followed by sequencing (V4 chemistry) on an Illumina HiSeq 2500 platform (Illumina) and in-house quality control and filtering of 75-bp paired-end generated reads. Filtered pair-end reads were aligned against the $12 \times$ reference genome [33] using Burrows-Wheeler Aligner with default parameters [34]. Read summarization was performed with htseq-count (version 0.6.0) with intersection non-empty settings [35] using the grapevine $12 \times$ genome assembly available from EnsemblPlants (http://plants.ensembl.org/Vitis_vinifera/ Info/Index). Differential gene expression analysis was carried out using edgeR (version 3.10.2) [36]. Genes were 
deemed differentially expressed (DE) between pairwise comparisons at a threshold of false discovery rate (FDR) $<0.05$. Transcript abundance was calculated as Fragments Per Kilobase of exon per Million (FPKM) mapped reads using edgeR. Transcripts having FPKM values $<0.5$ and assigned counts $<5$ were discarded.

\section{Clustering, functional enrichment, and promoter analysis}

Clustering of DE genes using edgeR's estimated gene expression (normalized counts) $\log 2$ fold change $(\log 2 \mathrm{FC})$ between small/large berries was performed using the kmeans method with 1000 iterations and the Speaman's rank correlation as the similarity metric. The latest grapevine gene annotations based the $12 \times$ V1 models were obtained from [37]. A separate functional annotation of transcripts was performed using the Mercator pipeline [38] to ascribe potential gene function and MapMan BINs [39] prior to gene enrichment analysis. MapMan BIN categories were considered significantly enriched (adjusted $P$-value $<0.05$ ) as determined by Fisher's exact test adjusted with Bonferroni correction for multiple testing correction. Based on the $12 \times$ grapevine genome assembly, all grapevine promoter sequences ( $1 \mathrm{~kb}$ upstream of the $5^{\prime}$ UTR) were retrieved from the CRIBI grape genome database (http://genomes.cribi.u nipd.it/grape/) [40]. Target sequences (cis-regulatory elements, CREs) of 63 plant transcription factors (TFs) representing 25 families recently characterized in Arabidopsis thaliana [41] and the ones from PLACE [42] were retrieved. These sequences were scanned in promoter regions of DE genes within clusters and selected gene families. Motif overrepresentation was calculated according to [43] using hypergeometric test and adjusted with false discovery rate (FDR) for multiple testing correction when appropriate. Putative CREs was considered significantly enriched if the associated FDR $<0.01$.

\section{Statistical analysis}

A one-way ANOVA was performed using JMP 7 (SAS Institute Inc.) to detect significant differences $(P<0.05$, $P<0.01, P<0.001)$ in berry components, E, TSS, and sugar, organic acid, and anthocyanin levels between small and large berries treatments at each sampling point.

\section{Results and discussion}

Analysis of physiological and compositional parameters between small and large berries

The diameters of all the berries considered in the experiment are reported in Fig. 1a. Berry diameter, total soluble solids (TSS, ${ }^{\circ}$ Brix), and elasticity (E) evolution in small and large berries during fruit development are
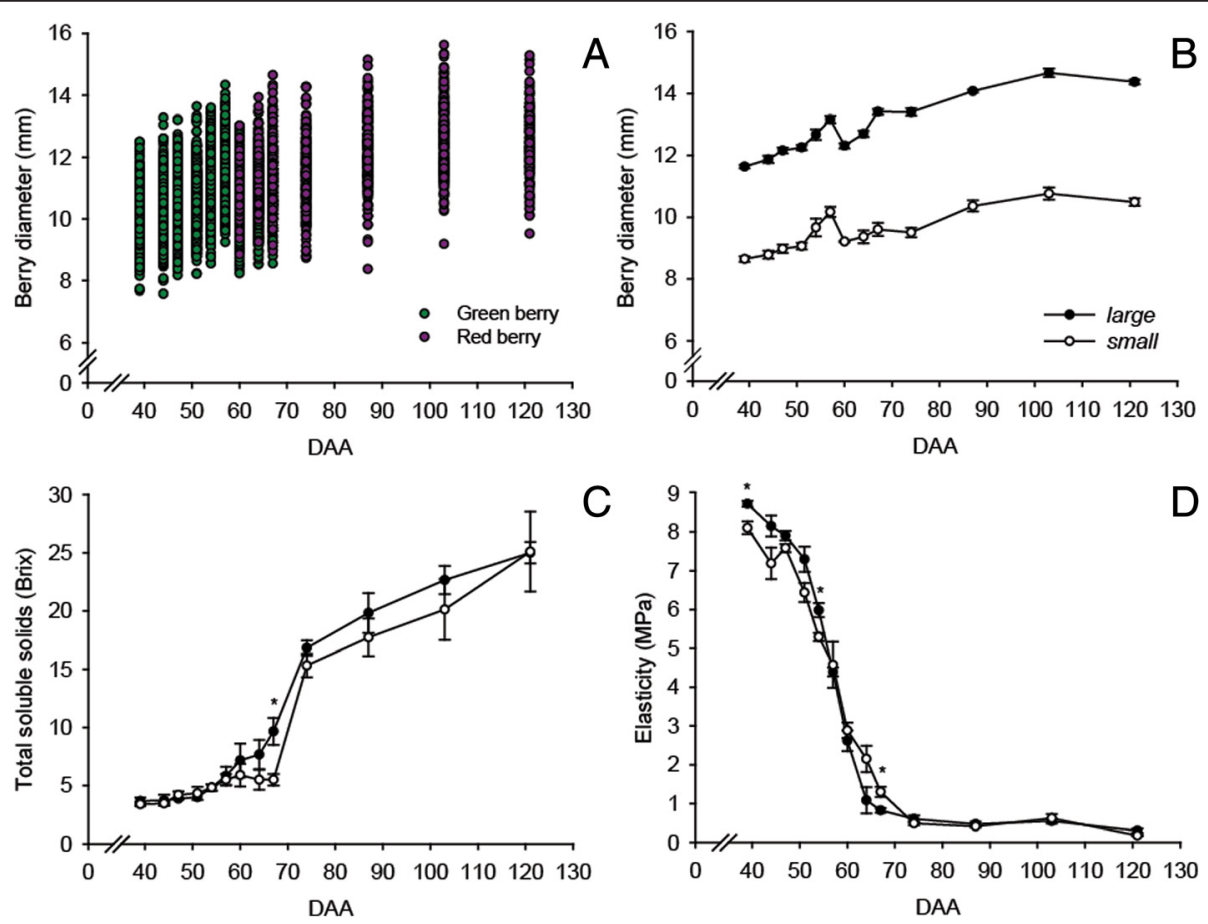

Fig. 1 Evolution of berry diameter, total soluble solids, and elasticity. (a) Berry diameter of the entire sampled population. (b) Diameter, (c) total soluble solids, and (d) elasticity of small and large berries during development. Green and purple indicates the recorded color of each individual berry. Means and standard errors are reported for each berry group at each developmental stage. ${ }^{*}$ indicates a significant difference $(P<0.05)$ between small and large berries 
reported in Fig. 1b, c, and d. Despite the differences in absolute values, the evolution of berry diameter was similar between small and large berries throughout the season (Fig. 1b). The TSS levels of small and large berries increased from 51 DAA until harvest (Fig. 1c). A faster increase in TSS was observed for large berries from 60 to 67 DAA. TSS levels of small berries remained relatively low until 67 DAA; afterward, a sharp increase was observed. E measures berry firmness, so a firm berry has higher $\mathrm{E}$ values (i.e. more pressure is required for a particular displacement), and as a berry softens E decreases [13, 31]. E of the small and large berries strongly decreased from 47 to 74 DAA, afterward the decrease was gradual (Fig. 1d). Differences in E levels and in the rate of $\mathrm{E}$ decrease between small and large berries were apparent at certain developmental stages. For example, at 39 and 54 DAA, large berries had higher E than small berries, while between 60 and 74 DAA, small berries had higher $\mathrm{E}$ than large ones. Although no significant differences in $E$ levels were observed at 54 and $57 \mathrm{DAA}$, a steeper drop of $\mathrm{E}$ was observed in large than in small berries from 54 to 74 DAA (Fig. 1d).

Berries from 47, 74, 103, and 121 DAA were selected for further physiological and biochemical analysis (Figs. 2 and 3 ). The skin to berry weight ratio was significantly higher in small than large berries at all four developmental stages (Fig. 2b); while large berries had significantly higher seed to berry weight ratios at 47 and 121 DAA (Fig. 2c). In addition, significant differences in the number of seeds/berry were observed between sizes, where large berries have more seeds (Fig. 2d), consistent with previous studies $[15,22]$.

Glucose and fructose levels increased sharply from 47 to $74 \mathrm{DAA}$ and continue to increase until $121 \mathrm{DAA}$ (Fig. 3a). Malic and tartaric acids (Fig. 3b and c) were at high levels at $47 \mathrm{DAA}$, and progressively decreased from 74 DAA onwards. The levels of sugars and organic acids reported here are comparable with the levels found in different cultivars at the same developmental stage [12, 21, 44]. No significant differences in the concentrations of sugars, glucose and fructose (Fig. 3a), and malic acid (Fig. 3b) were observed between small and large berries for any of the sampling dates. Tartaric acid concentration was significantly higher in small than in large berries at 47 and 103 DAA (Fig. 3c).

The total anthocyanin content (mg/g of skin) was significantly lower in small berries at 74 DAA (Fig. 3d). Although the recorded veraison $(50 \%$ of the berries display red pigmentation) date in the vineyard was 60 DAA, the large increase in sugar levels in large berries prior to 70 DAA (Fig. 1c) could have stimulated an earlier accumulation of anthocyanin in these berries [45, 46]. The accelerated drop in $\mathrm{E}$ observed in large berries, as well as the faster increase in sugar and anthocyanin levels, suggest that large berries approach ripening faster than small berries. Although the anthocyanin concentration in skins (mg/g skin) was similar between small and large berries at 103 and 121 DAA (Fig. 3d), small berries had a significantly higher anthocyanin concentration expressed as $\mathrm{mg} / \mathrm{g}$ of berry (Fig. 3e). Vice versa, total anthocyanin content, expressed as $\mathrm{mg} /$ berry, was higher in large berries (Fig. 3f). This suggests that the increase in anthocyanin concentration observed in small berries at 103 and 121 DAA was not due to a higher synthesis of these pigments but to the higher skin to berry weight ratio (Fig. 2b). This higher proportion of skin tissue determines the higher concentration of anthocyanin in small berries as observed in [19].

\section{Analysis of transcript differences between small and large berries}

To determine the influence of berry size on the berry skin transcriptome, Illumina mRNA sequencing was performed on berry skins at the four selected developmental stages $(47,74,103$, and 121 DAA). Using the $12 \times$ V1 genome as reference [33], an average of 34 million highquality paired-end reads per sample were successfully mapped, which typically corresponds to $92.5 \%$ of paired-end reads for each library (Additional file 1: Table S1). An average of 29 million paired-end reads per sample was assigned to transcripts. We detected the presence of 23,012 unique transcripts expressed in at least one of four developmental stages. Approximately $18,600,17,800,17,200$, and 17,150 transcripts were expressed in berry skins at 47, 74, 103, and 121 DAA, respectively.

A principal component analysis (PCA) was undertaken to analyze the level of similarity of the transcriptomes analyzed. The first three principal components explained a cumulative variance of $92.7 \%$; with the first, second, and third principal component explaining 71.2, 17.8, $3.7 \%$ of the variance, respectively (Fig. 4a). Inspection of the PCA plots revealed a clear separation of berry skin transcriptome based on the developmental stage and not on the biological variation within a developmental stage. Furthermore, a separation of the transcriptomes driven by the berry size was more evident at 47,74 , and 121 DAA, while it was undetected at 103 DAA. A total of 3482 unique genes (11.6\% of predicted transcriptome) were identified to be differentially $(\mathrm{FDR}<0.05)$ expressed between small and large berries in at least one developmental stage (Additional file 1: Table S2 and S3). A total of 2083 (557 downregulated, 1526 upregulated), 1244 (983 downregulated, 261 upregulated), 298 (57 downregulated, 241 upregulated) and 928 (375 downregulated, 573 upregulated) were differentially expressed (DE) between small and large berries at 47, 74, 103, and 


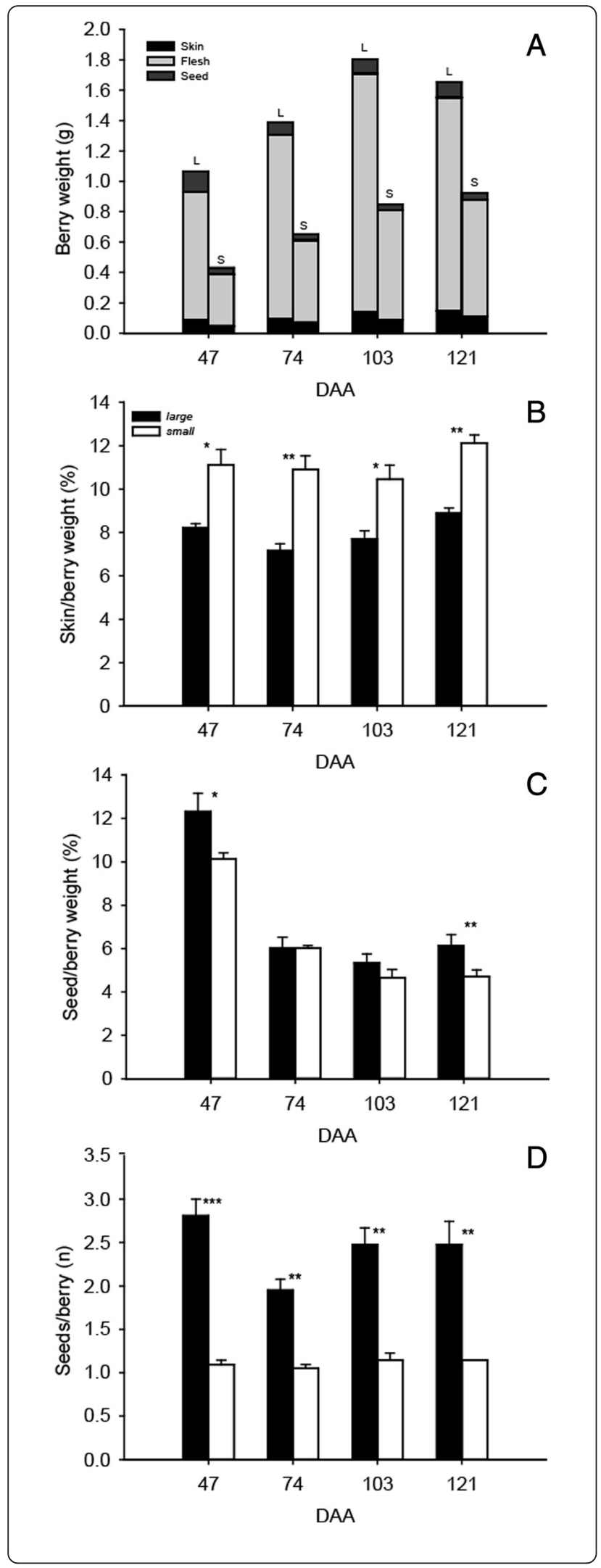

Fig. 2 Berry features. (a) Skin, flesh, and seed weight, (b) skin to berry weight ratio, (c) seed/berry weight ratio, and (d) seeds/berry number in small and large berries at 47, 74, 103, and 121 DAA. * **, and ${ }^{* *}$ indicate level of significance of $P<0.05, P<0.01$, and $P<0.001$, respectively

121 DAA, respectively (Fig. 4b). Gouthu et al. [47] demonstrated that differences in the ripening program (i.e. asynchrony) was reflected at the transcript level with large differential expression of berry transcripts when comparing between berry classes differing in softness and coloration at mid-veraison ( 69 DAA), regardless of tissue. These differences were drastically reduced to near zero at maturity. Our study revealed that differences in the skin transcriptomes between small and large berries are larger at earlier stages of development (47 and 74 DAA) than at later stages of development (103 and 121 DAA). This difference, together with the differences in fruit physiology and composition observed at the corresponding stages further suggests an asynchrony between small and large berries at early stages of development (Figs. 1a, d and 3c, d). The reduction of DE (from 47 to 103 DAA) suggests a process of resynchronization of the transcriptome between small and large berries during development. Interestingly, there was a second increase of the number of DE transcripts at 121 DAA. This might reflect the activation of an over-ripening/senescence program in the skins of small berries [28]. Cramer et al. [28] investigated the evolution of the skin transcriptome at late developmental stages, including overripening stages. Approximately $15 \%$ of the top 1000 $\mathrm{DE}$ genes were the same when results were compared between the DE genes between small and large berries at 121 DAA ( $25^{\circ}$ Brix) in this study and between 25 and $38{ }^{\circ}$ Brix in Cramer et al. [28], suggesting that small berries are ahead in ripening at these later stages.

Differentially expressed genes were clustered into 8 clusters based on their $\log 2$ fold change differences in small with respect to large berries at each development stage using the k-means clustering (Fig. 4c). Functional annotation of DE genes according to high-level MapMan ontology categories [39] showed that the largest proportion was involved in RNA regulation and protein metabolism (8-10\%), while transport, cell wall, signaling, and primary and secondary metabolism categories contributed between 5 and $8 \%$ of the total DE genes (Table 1, Additional file 1: Table S3). A total of 382 (of 2213) transcripts annotated as potential grapevine transcriptional regulators [37] were DE between small and large berries within each sampling date (Additional file 1: Table S3), indicating a difference in transcript regulatory programs between small and large berries. Validating 

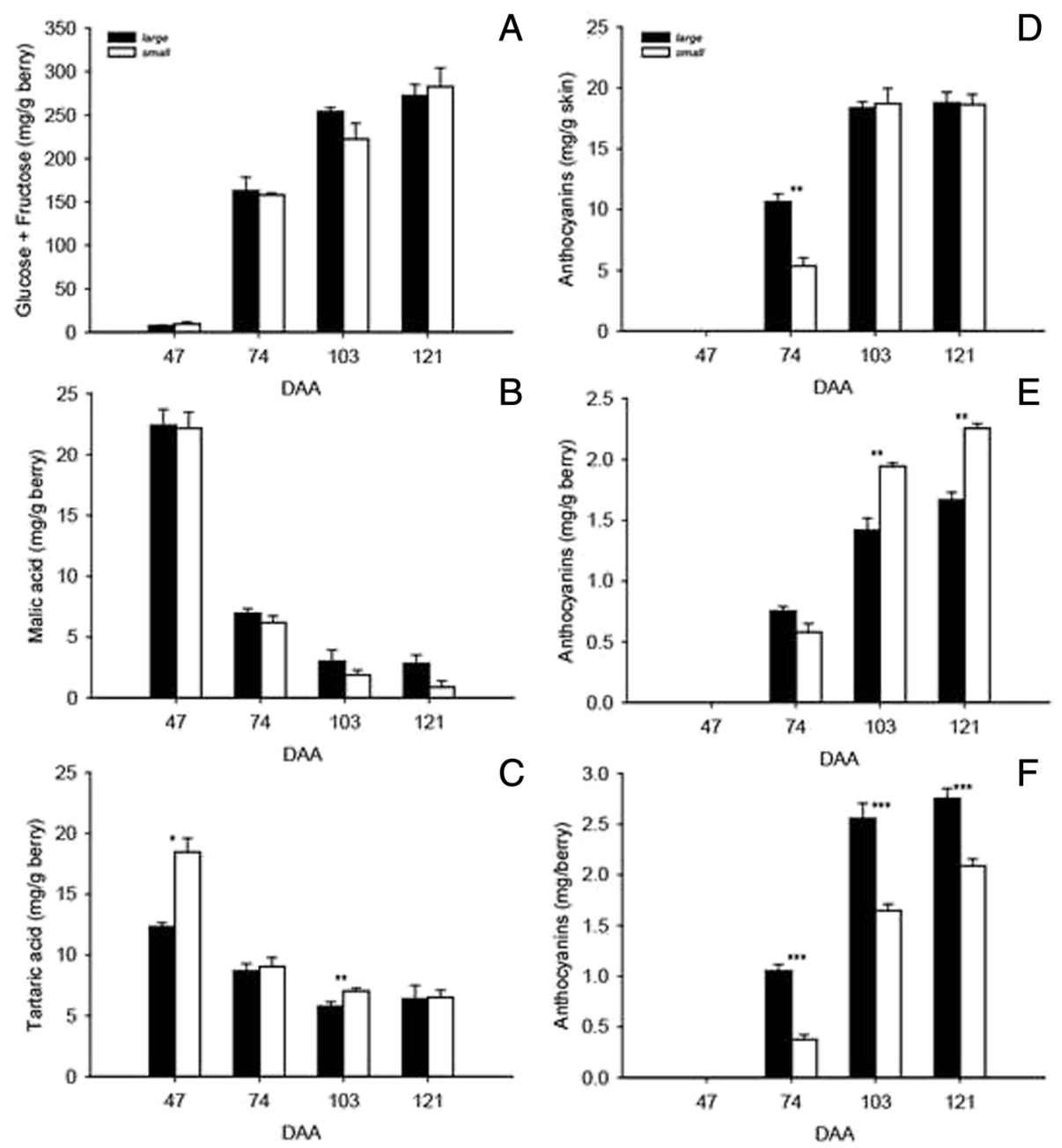

Fig. 3 Berry composition. (a) Glucose + fructose, (b) malic acid, and (c) tartaric acid concentration, expressed as mg/g berry, in small and large berries at 47, 74, 103, and 121 DAA. Anthocyanin levels expressed as (d) mg/g skin, (e) mg/g berry, and (f) mg/berry in small and large berries at $47,74,103$, and 121 DAA. Means and standard errors are reported for each berry group at each sampling. ${ }^{*}$,*, and ${ }^{* * *}$ indicate level of significance of $P<0.05, P<0.01$, and $P<0.001$, respectively

the observation that a large number of TF were DE between small and large berries, many cis-regulatory elements (CREs) related to binding sites of various TF families were also enriched among the DE genes (Table2, Additional file 1: Table S4), which may play an important role in the regulation of $\mathrm{DE}$ genes. The frequent occurrences of multiple enriched CREs within promoter regions of DE transcripts will be discussed further in the context of metabolic pathway regulation (see below).

Because of the observed differences between small and large berries at the physiological level and of the potential role of some of the DE genes on determining fruit and wine quality, we focused our discussion on pathways related to hormone metabolism and signaling, cell wall modifications, and flavonoid, stilbenoid, and fatty acid biosynthesis.

\section{Modulation of hormone metabolism and signaling in} small and large berries

Regulation of fruit development and ripening involves major metabolic changes regulated by complex interactions among hormones and not by a single hormone in isolation [48]. In grapes, ABA promotes berry ripening and auxins delay this process, while results on ethylene are mixed [5]. One hundred fifty-seven genes annotated to function in hormone metabolism (i.e. biosynthesis, degradation, signaling and transcriptional regulation; BIN 17) were DE between small and large berries (Additional file 1: Table S5). A total of 38, 42, and 29 transcripts related to ABA, auxin, and ethylene metabolism and signaling, respectively, were the most represented among hormone related genes, followed by $18,14,11$, and 6 transcripts related to jasmonic/salicylic acid, cytokinin, brassinosteroid, and gibberellin metabolism and signaling, 
A

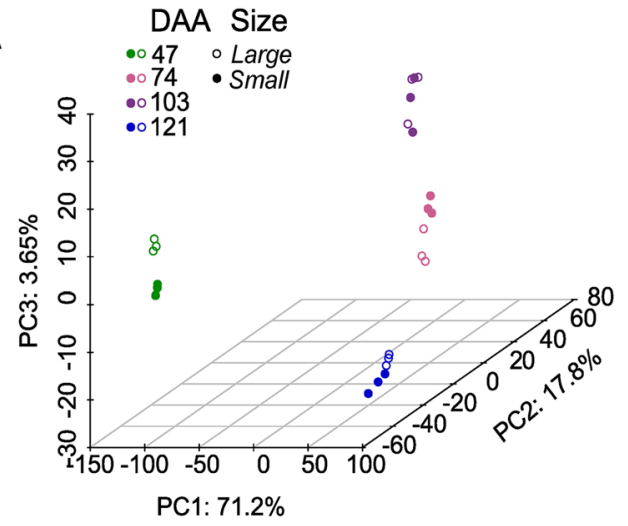

B

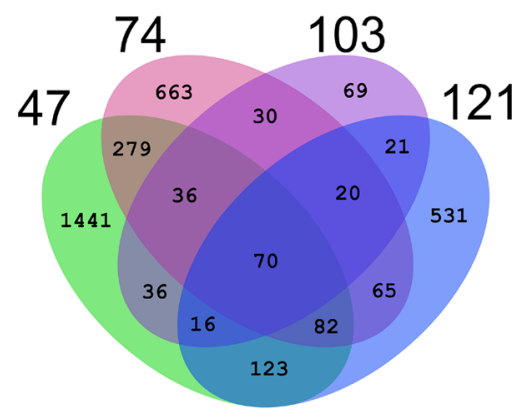

C

Log2
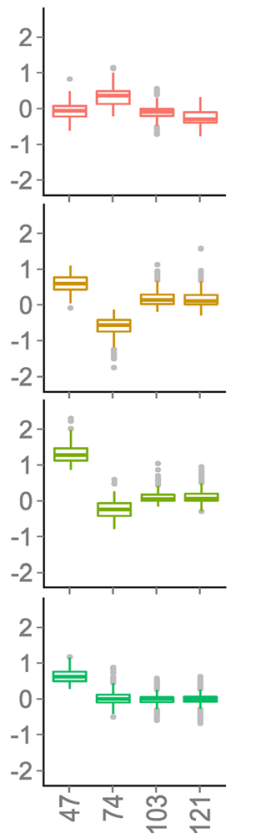

\section{Log2}

FPKM

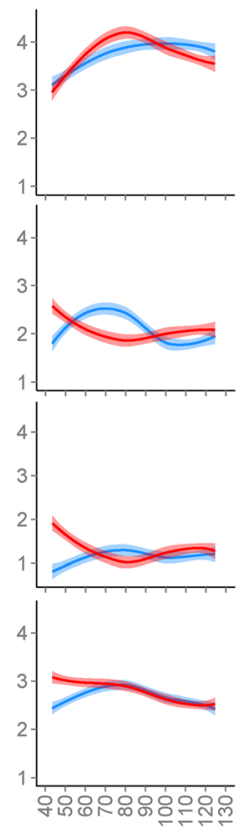

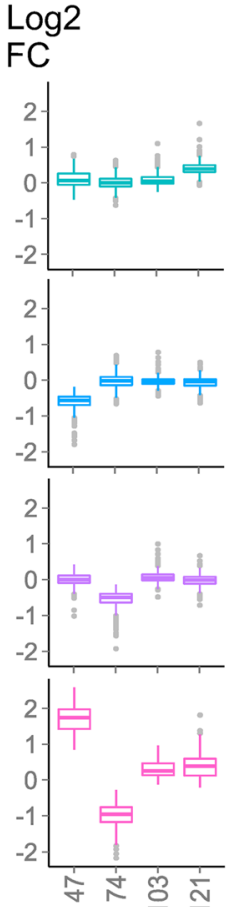

Log2

FPKM

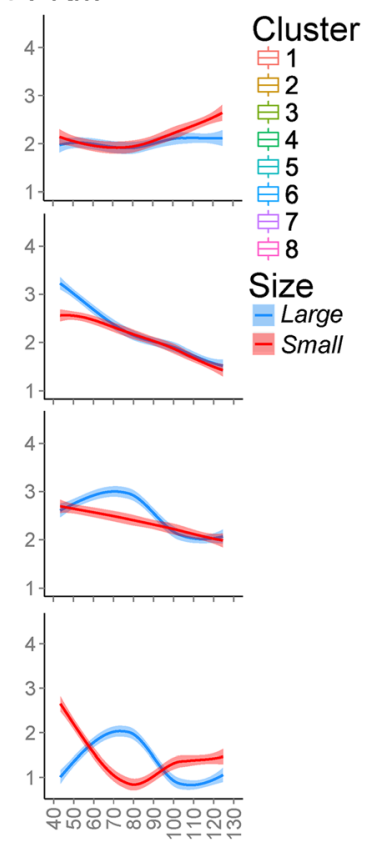

Fig. 4 Analysis of the berry skin transcriptome of small and large berries. (a) Principal component analysis (PCA) of the berry skin transcriptome of small (filled circles) and large (empty circles) berries at 47 (green), 74 (pink), 103 (purple), and 121 (blue) DAA. (b) The Venn diagram represents the common and unique genes differentially expressed between small and large berries at 47, 74, 103, and 121 DAA. Differentially expressed genes in each intersection of the Venn diagram are described in Additional file 1: Table S3. (c) The box plot and smoothed line plot represents the response of small versus large berries and dynamic change of gene expression during berry development, respectively. Differentially expressed genes were clustered using the k-means algorithm. The log2 fold changes between small and large and log2 (FPKM +1) values at 47, 74, 103, and 121 DAA

were used. Outlier log2 fold change values are represented as grey circles

respectively. Due to their major role in the ripening process [5], emphasis will be given to the transcripts involved in the biosynthetic pathways of ABA, auxin, and ethylene (Fig. 5).

Transcripts encoding structural enzymes of the ABA biosynthetic pathway were modulated during fruit development and were DE between small and large berries (Fig. 5a and b). Transcripts encoding 9-cis epoxycarotenoid dioxygenase (NCED) regulate ABA biosynthesis and the alteration of NCED expression have direct implications in ABA concentration and ripening-related traits in fruits [49]. The expression patterns of three DE NCED transcripts in the skin were distinct (Fig. 5a). For example, NCED2 (VIT_10s0003g03750) transcripts peak at 47 DAA and gradually decrease towards 121 DAA, NCED3 (VIT_19s0093g00550) transcripts peak at 74 DAA and again at 121 DAA, while NCED4 (VIT_02s0087g00910) transcripts progressively increase 
Table 1 Enrichment of MapMan functional categories (BINs) of k-means assigned clusters containing differentially expressed transcripts comparing skins of large and small berries. The table contains detailed information of the cluster size, BIN code and associated description, and the Bonferroni-adjusted $P$-value (Adj. P-value <0.05). Only high-level BINs are presented in this table (up to one decimal or depth =1)

\begin{tabular}{|c|c|c|c|c|}
\hline Cluster & Size & $\mathrm{BIN}$ & BIN name & Adj. P-value \\
\hline \multirow[t]{5}{*}{1} & 472 & 16 & secondary metabolism & 0.000476 \\
\hline & & 16.8 & secondary metabolism.flavonoids & $2.78 \mathrm{E}-07$ \\
\hline & & 18.2 & Co-factor and vitamine metabolism.thiamine & 0.043163 \\
\hline & & 20.2 & stress.abiotic & 0.005947 \\
\hline & & 33.1 & development.storage proteins & 0.002419 \\
\hline 2 & 342 & 5.3 & fermentation.ADH & 0.00028 \\
\hline 3 & 265 & NA & NA & NA \\
\hline \multirow[t]{5}{*}{4} & 884 & 10.7 & cell wall.modification & 0.00655 \\
\hline & & 27 & RNA & 0.008355 \\
\hline & & 27.3 & RNA.regulation of transcription & $2.15 \mathrm{E}-07$ \\
\hline & & 30 & signalling & 0.043608 \\
\hline & & 30.3 & signalling.calcium & 7.64E-05 \\
\hline \multirow[t]{2}{*}{5} & 320 & 16 & secondary metabolism & $1.54 \mathrm{E}-07$ \\
\hline & & 16.8 & secondary metabolism.flavonoids & $2.81 \mathrm{E}-08$ \\
\hline \multirow[t]{6}{*}{6} & 553 & 10 & cell wall & $8.42 \mathrm{E}-10$ \\
\hline & & 10.8 & cell wall.pectin*esterases & 0.002015 \\
\hline & & 26 & misc & 0.001691 \\
\hline & & 26.28 & misc.GDSL-motif lipase & 0.014839 \\
\hline & & 30 & signalling & 0.001752 \\
\hline & & 30.2 & signalling.receptor kinases & 0.000168 \\
\hline \multirow[t]{7}{*}{7} & 480 & 10 & cell wall & 0.002828 \\
\hline & & 10.6 & cell wall.degradation & 0.033172 \\
\hline & & 17 & hormone metabolism & 7.42E-05 \\
\hline & & 17.1 & hormone metabolism.abscisic acid & $1.1 \mathrm{E}-08$ \\
\hline & & 20.2 & stress.abiotic & 0.002289 \\
\hline & & 34 & transport & 0.025226 \\
\hline & & 34.4 & transport.nitrate & 0.024422 \\
\hline \multirow[t]{5}{*}{8} & 166 & 15 & metal handling & 0.00843 \\
\hline & & 33 & development & 0.041594 \\
\hline & & 33.99 & development.unspecified & 0.012587 \\
\hline & & 34 & transport & 0.005185 \\
\hline & & 34.12 & transport.metal & 0.024644 \\
\hline
\end{tabular}

towards 121 DAA. These observations were consistent with previous studies showing that NCED transcripts are under complex regulation in the berry $[10-12,50]$ and that expression of NCEDs is required to maintain in situ berry ABA biosynthesis. Several studies have highlighted that NCED3 is the enzymatic isoform which is correlated with berry ABA accumulation $[9,11]$. Therefore, the upregulation of this gene in small berries at 47 DAA may contribute to higher ABA levels at this stage; however, later during ripening when ABA levels are still high [11,
13, 47] no significant difference in NCED3 transcripts was observed in the skins of small and large berries. Instead, NCED2 transcripts were highly downregulated at 74 DAA in skins of small with respect to large berries. This might have contributed to differences in overall ABA accumulation and lower ABA accumulation in small berries at early stages of ripening would be consistent with the delay in sugar and anthocyanin accumulation observed at 67 and 74 DAA, respectively (Figs. 1 and 2). In addition, the downregulation of ripening-associated 
Table 2 Enrichment of PLACE- and PBM-curated cis-regulatory elements (CRE) of selected k-means assigned clusters containing differentially expressed transcripts comparing skins of small and large berries. The table contains detailed information on the number of promoters with the specified CRE, number of promoters in the genome containing the specified CRE, CRE sequence, false discovery rate (FDR), and the designated CRE name and regulatory description. A full description on the corresponding genes containing the associated CRE is available in Additional file 1: Table S4

\begin{tabular}{|c|c|c|c|c|c|c|}
\hline Cluster & Matches in sample & Matches in genome & FDR & Motif & Motif name & Regulation \\
\hline \multirow[t]{5}{*}{1} & 92 & 3331 & $9.67 \mathrm{E}-06$ & ACGTGKC & ACGTABREMOTIFA2OSEM & ABRE \\
\hline & 146 & 6199 & 9.67E-06 & CACGTG & CACGTGMOTIF & $\mathrm{bHLH} / \mathrm{bZIP}$ \\
\hline & 98 & 4120 & 0.000552 & AGATATTT & CCA1-1 & MYB-related \\
\hline & 33 & 1008 & 0.0024 & YACGTGGC & ABREATCONSENSUS & ABRE \\
\hline & 54 & 2115 & 0.004942 & CACGTGG & IRO2OS & $\mathrm{bHLH} / \mathrm{bZIP}$ \\
\hline \multirow[t]{8}{*}{4} & 109 & 1808 & $1.27 \mathrm{E}-10$ & CACGCG & MYC2-5 & bHLH \\
\hline & 397 & 10,397 & 7.44E-09 & MACGYGB & ABRERATCAL & ABRE \\
\hline & 469 & 13,792 & 0.000232 & GCCAC & SORLIP1AT & Light \\
\hline & 137 & 3331 & 0.000652 & ACGTGKC & ACGTABREMOTIFA2OSEM & ABRE \\
\hline & 286 & 7976 & 0.000884 & WTTSSCSS & E2FCONSENSUS & $\mathrm{E} 2 \mathrm{~F}$ \\
\hline & 227 & 6199 & 0.001528 & CACGTG & CACGTGMOTIF & $\mathrm{bHLH} / \mathrm{bZIP}$ \\
\hline & 120 & 3057 & 0.005201 & GAGTGAG & SORLIP5AT & Light \\
\hline & 303 & 8835 & 0.005201 & CTGACY & WBOXNTCHN48 & WRKY \\
\hline 5 & 154 & 10,397 & $9.78 \mathrm{E}-05$ & MACGYGB & ABRERATCAL & ABRE \\
\hline \multirow[t]{8}{*}{6} & 131 & 4411 & $1.51 \mathrm{E}-06$ & TGTCGG & ETT-1 & ARF \\
\hline & 149 & 5482 & $1.95 \mathrm{E}-05$ & ACCGAC & DRE2COREZMRAB17 & AP2/ERF \\
\hline & 185 & 7231 & $1.95 \mathrm{E}-05$ & RCCGAC & DRECRTCOREAT & AP2/ERF \\
\hline & 285 & 12,862 & 0.000589 & RYCGAC & CBFHV & AP2/ERF \\
\hline & 325 & 15,123 & 0.000887 & CCWACC & MYBPZM & MYB \\
\hline & 248 & 11,172 & 0.002184 & ACCWWCC & BOXLCOREDCPAL & MYB \\
\hline & 128 & 5288 & 0.006668 & TGTCGA & $\mathrm{ETT}-2$ & ARF \\
\hline & 46 & 1504 & 0.0082 & GGNCCCAC & TCP15 & $\mathrm{TCP}$ \\
\hline \multirow[t]{5}{*}{7} & 67 & 2312 & 0.000349 & GCCGAC & RAP2.3-3 & AP2/ERF \\
\hline & 153 & 7231 & 0.003952 & RCCGAC & DRECRTCOREAT & AP2/ERF \\
\hline & 116 & 5288 & 0.005831 & TGTCGA & ETT-2 & ARF \\
\hline & 202 & 10,397 & 0.008081 & MACGYGB & ABRERATCAL & $\mathrm{bZIP/bHLH}$ \\
\hline & 241 & 12,862 & 0.008373 & RYCGAC & CBFHV & AP2/ERF \\
\hline
\end{tabular}

NCED4 gene in small compared to large berries from 103 DAA onwards might also reflect the lower ABA biosynthetic capacity of small compared to large berries at 103 and 121 DAA. Nevertheless, NCED2 was observed to be upregulated in small compared to large berries at 121 DAA. Collectively, different sized berries exhibit a different regulation of NCED transcripts, and significantly lower NCED transcripts levels were found in small berries than in large ones during berry ripening, especially at 74 DAA, with potential effects on the ripening process.

The genes encoding TRYPTOPHAN AMINOTRANSFERASE OF ARABIDOPSIS1/TRYPTOPHAN AMINOTRANSFERASE RELATED (TAA1/TAR) and YUCCA (YUC) are critical for regulating auxin levels and ripening in young berries [7]. The expression of transcripts encoding TAA1/TAR1 - 4 and YUC1 throughout berry development ( 2 to 16 weeks post flowering) have also been reported in Shiraz berries [7]. These genes were modulated during fruit development and were also DE between small and large berries in this study (Fig. 5a and b). Three TAA/TAR transcripts (TAR2, 3, and 4) and another (TAR1) peaked in the skins of berries harvested at 47 and 103 DAA, respectively. One YUC transcript (VIT_04s0008g03920) was specifically present at 47 DAA, another YUC transcript (VIT_07s0104g01250) peaked around veraison (74 DAA), and other two YUCs (VIT_07s0104g01260 and VIT_04s0023g01480) were mostly present during late ripening. These observations were consistent with previous studies showing TAA/TAR and $Y U C$ transcript evolution and auxin accumulation 

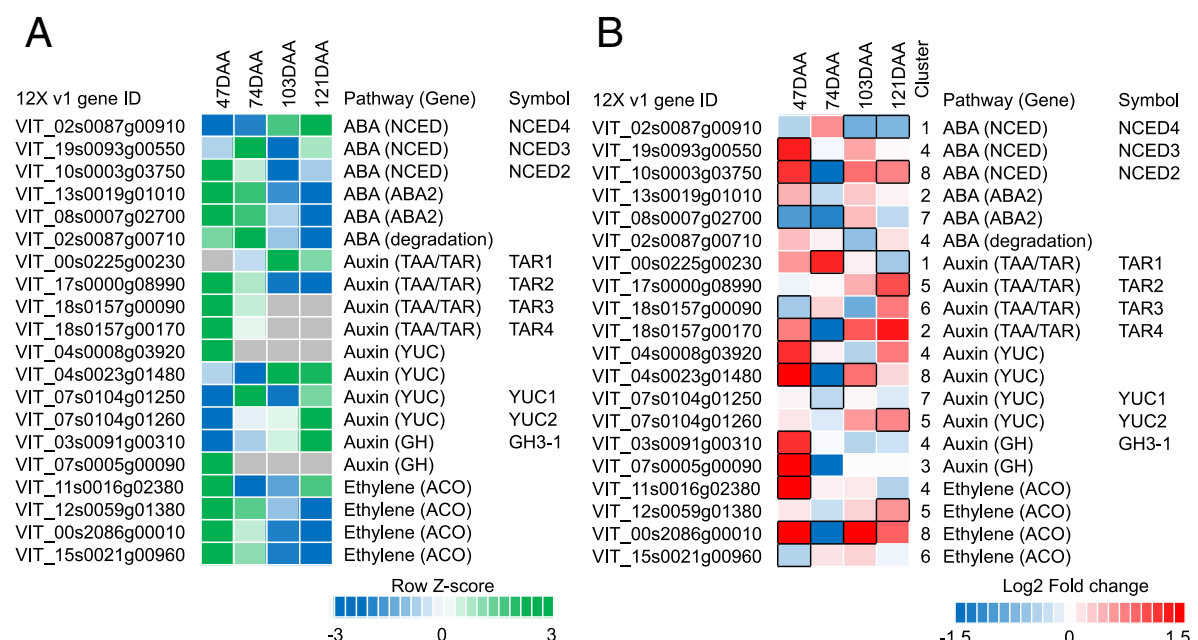

Fig. 5 Evolution during development and fold change between small and large berries of abscisic acid (ABA), auxin, and ethylene genes differentially expressed at 47, 74, 103, and 121 DAA. (a) Evolution, based on the mean log2 (FPKM + 1) of small and large berries, and (b) log2 fold (small/large) changes. The relative log2 (FPKM +1$)$ values registered in small and large berries on average during berry development in a are depicted by green (high expression) and blue (low expression). Grey color indicates the absence

(or low levels) of detectable transcripts at the corresponding stage. Blue and red colors in $\mathbf{b}$ indicate downregulated and upregulated transcripts, respectively, in small berries in relation to large berries. Boxes with bold margins indicate significant differences (adjusted $P$-value $<0.05$ ) between berry size treatments at a given developmental stage. The cluster column in $\mathbf{b}$ indicates the cluster number the associated transcript belongs to NCED, 9-cis-epoxycarotenoid dioxygenase; ABA2, xanthoxin dehydrogenase; TAA/TAR, TRYPTOPHAN AMINOTRANSFERASE OF ARABIDOPSIS1/ TRYPTOPHAN AMINOTRANSFERASE RELATED (TAA1/TAR); YUC, YUCCA; GH, IAA-amido synthetase; ACO, 1-aminocyclopropane-1-carboxylic acid oxidase

during berry development and ripening [7]. At 47 DAA, when auxins levels are high, transcripts encoding TAR4 (VIT_18s0157g00170) and a YUC (VIT_04s0008g03920) were highly upregulated in small with respect to large berries. Similarly, TAR1 (VIT_00s0225g00230) transcripts were also upregulated at 74 DAA. However, TAR3 (VIT_18s0157g00090) transcripts, which have been shown to relate with the accumulation of auxin at early stages [6], were downregulated in small with respect to large berries at 47 DAA. Several studies have indicated that auxin conjugation through the action of IAA-amido synthetases (GH3), which conjugates aspartic acid to auxin, is critical for ripening initiation and the regulation of auxins in the berry during development [51, 52]. Interestingly, GH3-1 transcripts (VIT_03s0091g00310) which display a ripening-associated developmental accumulation were significantly upregulated in the skins of small compared to large berries. Therefore, significant differences in ripening physiology of the two berry classes (Figs. 1, 2, and 3) and significant modulation of auxin metabolic pathways points to the possible involvement of auxin and its conjugates in determining asynchrony between berries of different sizes.

The biosynthesis of ethylene is determined, in part, by the action of 1-aminocyclopropane 1-carboxylate (ACC) oxidase (ACO), a key enzyme involved in the production of ethylene using ACC as precursor [48]. Several ACO-encoding members were also DE between small and large berries (Fig. 5b), many of which exhibit highest expression at 47 DAA followed by a gradual decrease until 103 DAA (Fig. 5a). Although grapevine is a non-climacteric fruit, previous findings have shown an increase of ACO activity and ethylene production at stages before veraison $[8,9]$. Two ACO transcripts (VIT_11s0016g02380 and VIT_00s2086g00010) displayed strong upregulation at 47 DAA in small compared to large berries. This might provide evidence that in small berries at preveraison stages a higher production of ethylene may in fact be delaying the ripening process and not enhancing ripening, as exemplified by the delayed sugar accumulation at 68 DAA and the lower anthocyanin levels at 74 DAA in small berries (Fig. 3). Indeed, recent studies have demonstrated application of ethylene at pre-veraison stages delays ripening through the activation of auxin biosynthesis pathways, significantly postponing sugar and anthocyanin accumulation, as well as the berry growth [7, 53, 54]. Ethylene may also play a role later in ripening, especially in the skin, as the abundance of many transcripts involved in ethylene biosynthesis and signaling peaked from $23{ }^{\circ}$ Brix onwards, stages when desirable flavor and aroma compounds accumulate [28]. In this study, the significant upregulation of two $A C O$ transcripts (VIT_12s0059g01380 and VIT_00s2086g00010) from 103 DAA onwards, indicates that ethylene might contribute to the induction of pathways important for 
fruit flavor in the skin of small berries compared to large ones [28].

Among hormone related transcription factors, the grapevine bZIP TF, VvABF2, have been shown to modulate ABA-dependent berry ripening processes through the induction of cell wall hydrolytic enzymes and complex modulation of multiple hormonal pathways including ABA, auxin, and ethylene [55]. Expression of $V v A B F 2$ transcript (VIT_18s0001g10450) was highest at 74 DAA corroborating its ripening-associated expression and its role in berry ripening (Additional file 1: Table S3). Interestingly, $V v A B F 2$ was first upregulated in small berries at $47 \mathrm{DAA}$ and subsequently downregulated at 74. DAA compared to large berries. This modulation might mediate the altered hormonal metabolism profiles involving NCED, TAA $Y U C$, and $A C O$ transcripts between small and large berries at 47 and 74 DAA. Also, the regulation of cell wall degradation and expansion via ABF2 may explain the slower softening rate experienced in small compared to large berries observed at the onset of fruit ripening.

In summary, the differential regulation of several NCED, TAA/YUC, and ACO transcripts between the berry size classes suggest that hormonal pathways are differential regulated and might therefore contribute to variations in $\mathrm{ABA}$, auxin, and ethylene levels in the skin of small and large berries with potential effects on skin metabolism and composition. However, additional studies with intensive sampling strategies and measurement of these hormones in the two berry classes will be needed to gain a deeper understanding on the relative contribution of each hormone and its influence on berry size and fruit composition traits.

\section{Modulation of cell wall metabolism in small and large berries}

In fleshy fruits, the remodeling of cell wall architecture during fruit development affects fruit softening [56] and involves concerted changes in cell wall-related gene expression and multiple enzyme activities [48]. Influence of berry skins in determining post-veraison berry growth $[57,58]$ and the role of cell wall degradation and modification enzymes in mediating this process [59] have been previously reported. The altered transcriptional profiles of cell wall genes in skins between small and large berries highlights the potential role of cell wall modification genes in modulating berry growth and softening.

In this study, more than 120 annotated cell wall (BIN 10) transcripts exhibited DE between small and large berries during fruit development (Additional file 1: Table S5). Transcripts related to cellulose synthesis (BIN 10.2), cell wall modification (BIN 10.7), degradation (BIN 10.6), and pectin esterification (BIN 10.8) were significantly modulated among the berry size classes in these clusters. A decrease in berry $\mathrm{E}$ has been shown to be the earliest ripening-associated event observed at the onset of ripening [13]. Emphasis will be given on the cell wall genes differentially expressed at 74 DAA (Fig. 6a-d), given that this is the developmental stage that immediately follows the large decrease in berry $\mathrm{E}$ and the stage when small and large berries displayed differences in $\mathrm{E}$.

We observed that 17 cell wall degradation genes (BIN 10.6.2 and BIN 10.6.3), consisting of six xyloglucan endo-transglycosylase/trans-hydrolase, two 1,4-betamannan endohydrolase, five pectate lyases, and three polygalacturonases, were downregulated in skins of small compared to large berries at 74 DAA (Fig. 6a and b). This observation may reflect lower cell wall degradation activity in small than in large berries, which supports the slower rate of softening from 60 to 74 DAA. Pectin degrading enzymes, such as polygalacturonases and pectate lyases, are two principal enzymes involved in tomato fruit softening through active cell wall pectin de-polymerization [56]. Studies in tomato [60], apple [61], and strawberries [62] have demonstrated that silencing of polygalacturonase gene expression does not always affect fruit softening. Pose et al. [62] found large differences in strawberry fruit firmness at harvest in strawberry polygalacturonase 1 -suppressed lines, but the changes in firmness in tomato during softening were very small [60] and in apple most transgenic polygalacturonase suppression lines had no effect on fruit firmness [61]. Nevertheless, silencing of pectate lyases transcripts result in firmer fruits both during softening and at harvest $[63,64]$.

In plants, the transcription factor APETALA2/ Ethylene Responsive Factor (AP2/ERF) belongs to a multigenic family involved in the control of metabolism, stress response, and plant development through the binding of DRE and GCC-related motifs in promoters regions of regulatory targets (reviewed in [65]). Several studies in fruits have demonstrated that AP2/ERF TFs contribute in regulating ripening-related processes, especially fruit softening, by targeting cell wall degradation genes (reviewed in [48]). In this study, significant enrichment of ethylene related CREs, such as DRECRTCOREAT, CBFHV, and LTRECOREATCOR15 (Fig. 6e, Additional file 1: Table S4), in cluster 7 genes also corresponds to the presence of AP2/ERF CREs in promoter regions of seven (three 1,4-beta-mannan endohydrolase, two pectate lyases, and two polygaluacturonase) predicted cell wall degrading transcripts. In agreement, we observed eight DE AP2/ERF TFs which were significantly downregulated in small compared to large berries at 74 DAA; four of which were ripening-associated (Additional file 1: Table S3). This suggest that AP2/ERF TFs may be critical in regulating cell wall degrading 


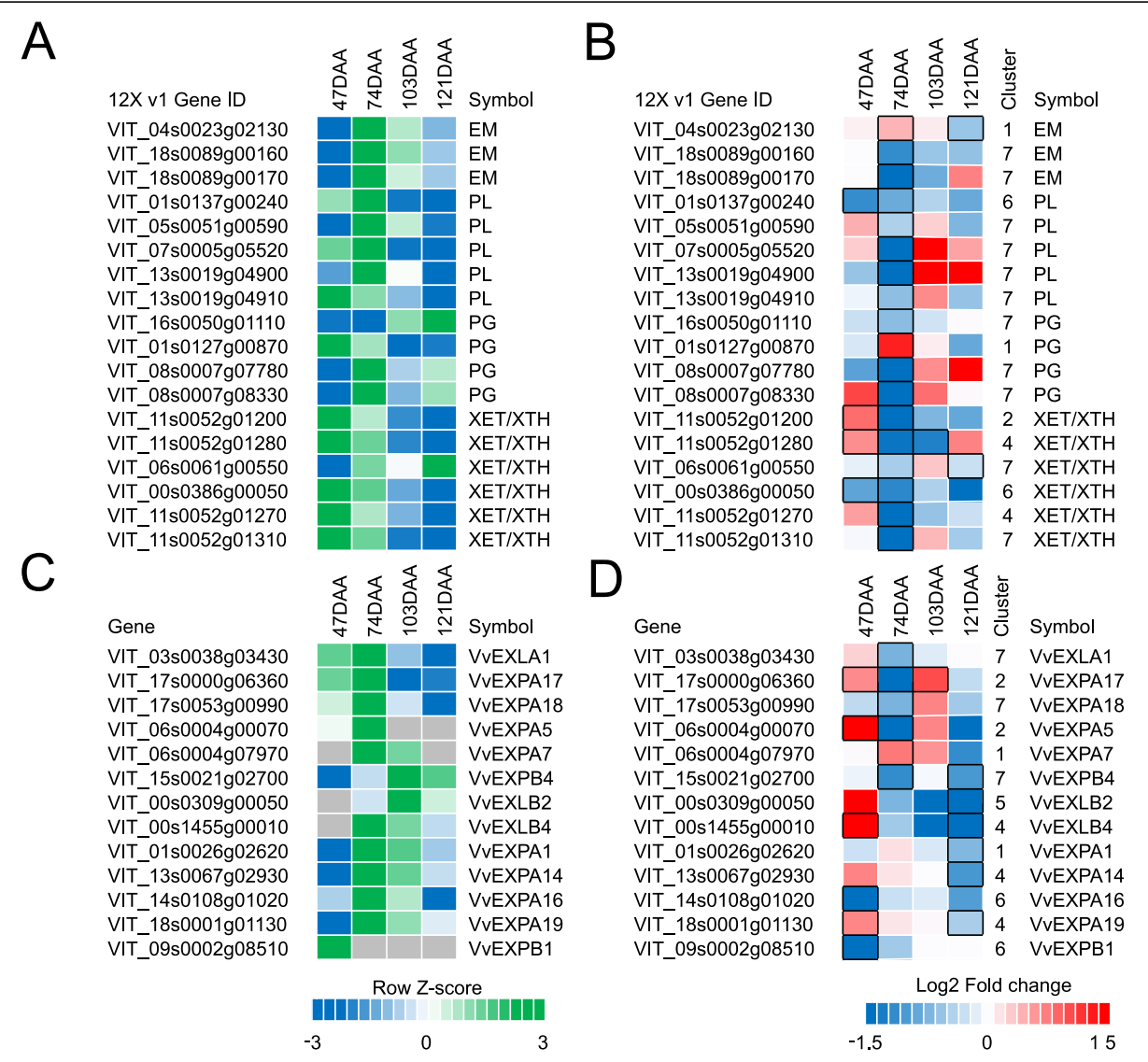

E
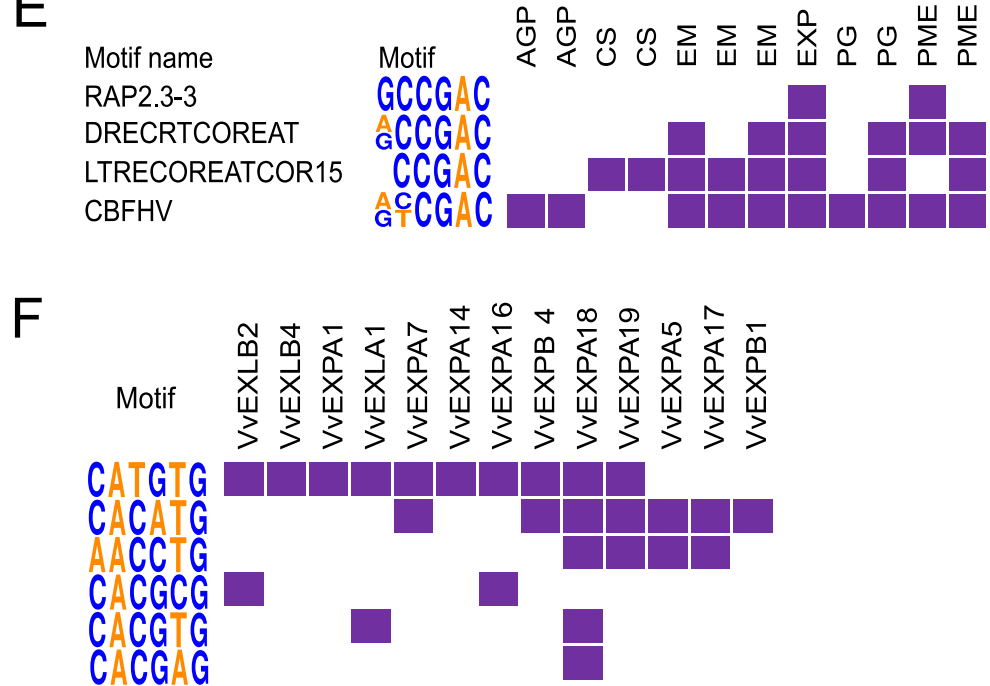

Fig. 6 Evolution during development, fold change values between small and large berries, and selected cis-regulatory element profile of cell wall transcripts differentially expressed at 47,74, 103, and 121 DAA. The heat map represents the evolution (a and $\mathbf{c}$ ), based on the mean log2 (FPKM +1 ) of small and large berries, and log2 fold (small/large) changes ( $\mathbf{b}$ and $\mathbf{d})$ of cell wall degradation (a and $\mathbf{b})$ and modification (c and $\mathbf{d})$ genes. The relative log2 $(F P K M+1)$ values registered in small and large berries on average during berry development in $\mathbf{a}$ and $\mathbf{c}$ are depicted by green (high expression) and blue (low expression). Grey color indicates the absence (or low levels) of detectable transcripts at the corresponding stage. Blue and red boxes in $\mathbf{b}$ and $\mathbf{d}$ indicate downregulated and upregulated transcripts, respectively, in small berries in relation to large berries. Boxes with bold margins indicate significant differences (adjusted $P$-value $<0.05$ ) between small and large berries at a given developmental stage. The cluster column in $\mathbf{b}$ and $\mathbf{d}$ indicates the cluster number the associated transcript belongs to. EM, 1,4-beta-mannan endohydrolase; PL pectate lyase; PG Polygalacturonase; XET/XTH Xyloglucan endotransglucosylase/hydrolase. (e and $\mathbf{f}$ ) The heat map illustrates the presence of AP2/ERF and bHLH/NAC cis regulatory elements in cell wall genes. Purple and white colors depict the presence and absence of the respective CRE in the promoter regions of the gene 
transcripts in grapevines, and differences in AP2/ERF TF regulation between small compared to large berries prior to ripening, may have affected the progression of softening reaching this stage (Fig. 1d).

Expansins act as primary cell wall loosening agents and incorporators of new cell wall material during the first growth phase and as mediators of cell wall disassembly by facilitating the contact between cell wall material and degradation enzymes during stage III of growth in grapevine berries $[59,66]$. The grapevine genome contains 29 expansin genes classified into four distinct subfamilies (expansin A, expansin B, expansin-like A, and expansin-like B) [67], of which two grapevine expansins were demonstrated to promote cell expansion [68]. Many cell wall expansin transcripts (BIN 10.7) were highly expressed at 74 DAA and six of these transcripts were significantly downregulated in skins of small with respect to large berries. Moreover, other six transcripts were downregulated at 121 DAA when their level of expression was on average low (Fig. 6c and d). The downregulation of expansin transcripts observed in the skins of small compared to large berries at 74 and 121 DAA indicates that cell wall loosening in the skin may be generally reduced, potentially limiting skin and mesocarp expansion and resulting in smaller berries. Indeed, fruits of tomatoes overexpressing expansin displayed enhanced softening and were significantly larger compared to controls at various stages of fruit development [69].

The regulation of some expansin transcripts such as EXPA19 (VIT_18s0001g01130) and EXPB4 (VIT_15s0021g02700) by VvCEB1 have also been proposed [55, 70]. Analysis of $V \nu C E B 1$, a fruit ripening-specific bHLH transcription factor, gene expression from 10 different varieties exhibiting differences in berry size revealed a strong correlation between fruit size and $V \nu C E B 1$ transcript accumulation [71]. In this study, $V \nu C E B 1$ transcript (VIT_01s0244g00010) reached a maximum at 74 DAA and slowly decreased until 121 DAA (Additional file 1: Table S3). $V \nu C E B 1$ was downregulated in skins of small compared to large berries at 74 and 121 DAA, but were only significant at 121 DAA. The down regulation of $V v C E B 1$ in small berries at 74 and 121 DAA paralleled the down regulation of many expansin transcripts. Promoter analysis performed on DE expansins for bHLHrelated CRE revealed that the CATGTG element, a typical DNA binding domain for bHLH TFs [72], was enriched in the promoter region of 10 out of $13 \mathrm{DE}$ expansin genes (Fig. 6f, Additional file 1: Table S4). This suggests that upstream control of expansins differentially expressed in small and large berries may in part be mediated by VvCEB1 during ripening. Nevertheless, previous studies have also shown that NAC TFs can bind specifically to CATGTG elements [73], which might provide evidence for the regulation of expansin transcripts by NAC TFs. We observed that the majority of NACs, such as a ripening-associated NAC26 (VvNAC26, VIT_01s0026g02710) which is highly expressed at 74 and 103 DAA, were downregulated in small compared to large berries at 74 DAA in parallel with downregulation of several expansin genes (Additional file 1: Table S3). A recent study has also shown that polymorphisms in $V v N A C 26$ were associated with berry size variation among 114 grapevine varieties [74]. Together, this transcriptional network involving bHLH and NAC TFs may be critical for regulating berry growth and size determination in grapevine.

\section{Modulation of flavonoid and stilbenoid pathways in small and large berries}

Flavonoids and stilbenes are plant secondary metabolites commonly found across the plant kingdom. These specialized metabolites fulfill diverse physiological roles in stress response, as antioxidants, and during reproduction [75]; in grapevine, they strongly affect grape and wine quality [76]. We observed that differences in berry size were related to large differences in the expression of flavonoid genes (Fig. 7, Additional file 1: Table S5). The DE flavonoid genes were predominantly assigned to clusters 1 (19 genes) and 6 (5 genes).

Three chalcone synthases (CHSs; VIT_07s0151g01060, VIT_13s0067g02870, and VIT_13s0067g03820), and three chalcone isomerases (CHIs; VIT_05s0136g00260, VIT_14s0068g00920, and VIT_14s0068g00930) -coding genes were differentially modulated in small and large berries. One CHS (VIT_13s0067g02870) and one CHI (VIT_05s0136g00260) were downregulated in small relative to large berries at 47 DAA when the pathway precursors are used for the production of flavan-3-ol and proanthocyanidins. Later during development, one $\mathrm{CHS}$ (VIT_13s0067g03820) was upregulated at 74 DAA, while two (VIT_07s0151g01060 and VIT_13s0067g02870) out of three CHSs and all the CHIs mentioned above were downregulated in small in comparison to large berries at 121 DAA.

Of the total 16 flavonoid $3^{\prime} 5^{\prime}$-hydroxylases (F3'5' $\mathrm{Hs}$ ) found in the grapevine genome, we observed seven $F 3^{\prime}$ 5' $H$ transcripts (VIT_06s0009g02810, VIT_06s0009g02840, VIT_06s0009g02860, VIT_06s0009g02880, VIT_06s0009g0 2920, VIT_06s0009g02970, and VIT_06s0009g03010) that were significantly downregulated in small berries at 103 and 121 DAA (Cluster 1). Similarly, two flavonoid 3'-hydroxylases (F3'Hs; VIT_17s0000g07200 and VIT_ 17s0000g07210) and one flavanone 3-hydroxylase (F3H; VIT_04s0023g03370) -coding genes, were also significantly downregulated in small berries at 121 DAA (Cluster 1). F3' $5^{\prime} \mathrm{H}$ and F3' $\mathrm{H}$ enzymes have been shown to be critical in determining the accumulation of di- and tri-hydroxylated flavonoids and the ratio between blue and red anthocyanin 


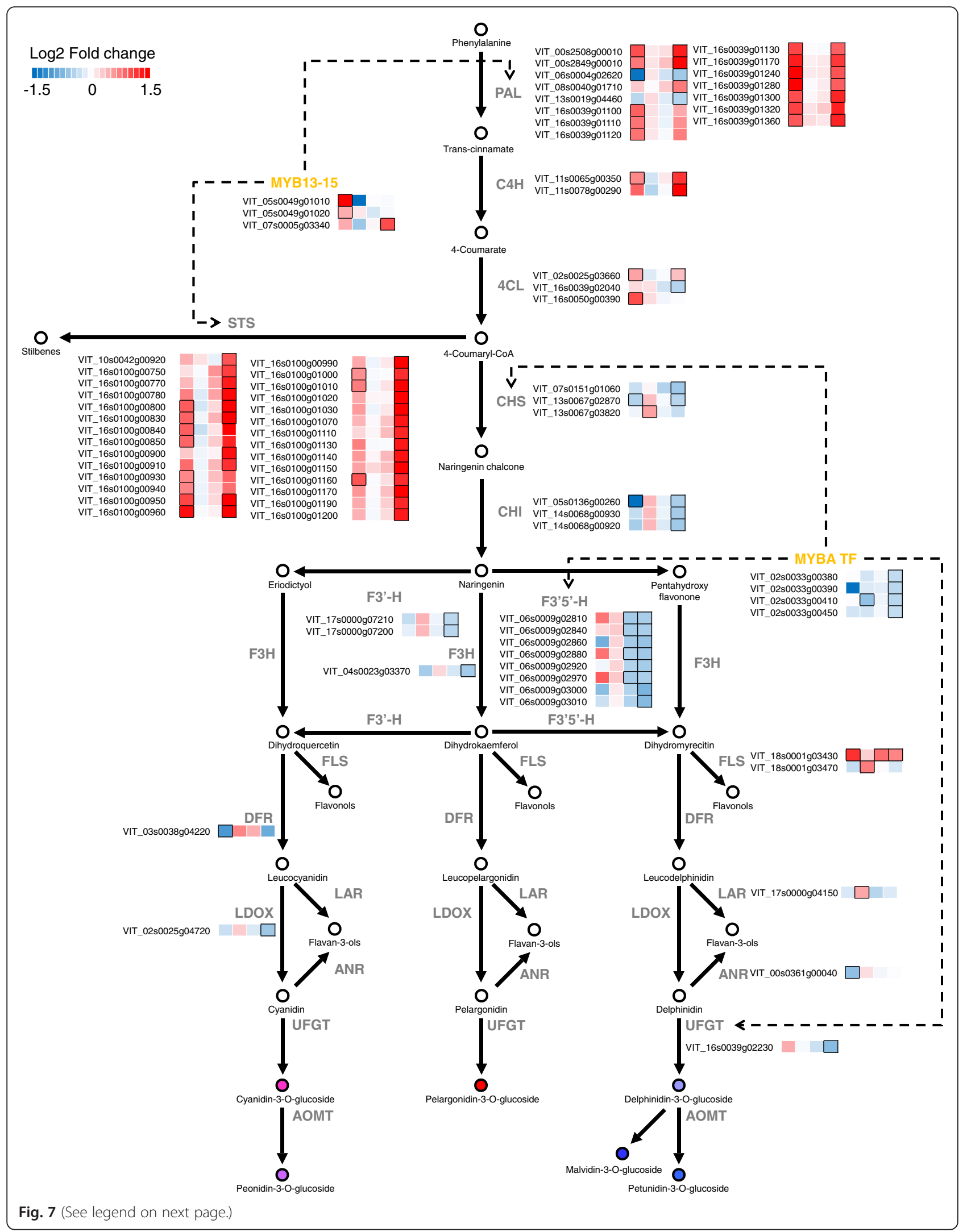


(See figure on previous page.)

Fig. 7 Modulation in berry skin transcripts involved in the phenylpropanoid and flavonoid pathway in small and large berries at 47, 74, 103, and 121 DAA. Blue and red boxes indicate downregulated and upregulated transcripts, respectively, in small berries in relation to large berries. Boxes with bold margins indicate significant differences (adjusted $P$-value $<0.05$ ) between berry size treatments at a given developmental stage. Transcription factors (colored in yellow) involved in the regulation of the phenylpropanoid and/or the flavonoid pathway transcripts are depicted in dotted lines. PAL Phenylalanine lyase; C4H Cinnamate-4-hydroxylase; 4CL 4-Coumarate:coenzyme A ligase; CHI Chalcone isomerase; CHS Chalcone synthase; F3H Flavanone 3-hydroxylase; F3'H Flavonoid 3'-hydroxylase; F3'5'H Flavonoid 3'5'-hydroxylase; FLS flavonol synthase; DFR Dihydroflavonol 4-reductase; LAR Leucoanthocyanin reductase; LDOX Leucoanthocyanin dioxygenase; UFGT UDPglucose:flavonoid 3-O-glucosyltransferase; and AOMT Anthocyanin O-methyltransferase. All other information is available at Additional file 1: Table S5

in grapes [77-79]. The simultaneous downregulation of both $F 3^{\prime} H$ and $F 3^{\prime} 5^{\prime} H$ transcripts in small compared to large berries, particularly at $121 \mathrm{DAA}$, did not affect the relative abundance of the different anthocyanin forms (data not shown). Flavonol synthase (FLS) is the key enzyme for the production of flavonols in grapevines [80]. Of the five FLS transcripts encoded in the genome, the two transcriptionally active FLS (VIT_18s0001g03470 and VIT_18s0001g03430) exhibited a ripening-associated accumulation in the skin (Additional file 1: Table S5); similar to that observed in previous studies in developing grape berries [80, 81]. Transcripts encoding grapevine FLS5 (VIT_18s0001g03430) were significantly upregulated in small berries at 47, 103, and 121 DAA (Fig. 7). Similarly, the FLS4 (VIT_18s0001g03470) gene was significantly upregulated in small with respect to large berries at 74 DAA. Previous studies have shown that FLS transcript expression provides an excellent indicator for cluster light exposure and marker for flavonol synthase activity given strong positive relationship (correlation) of solar radiation intensity with FLS transcripts and flavonol content in berry skins $[82,83]$. In the current study, berries of different sizes were harvested from the same clusters controlling for differences in microclimate among berries. Thus differences in FLS expression between berries of different sizes must have arose from endogenous mechanisms. Consistently, previous studies reported that wine produced from small berries contain more flavonols compared to wines obtained from medium and large berries [24].

The expression level of key flavan-3-ol/proanthocyanidin genes codifying for leucoanthocyanidin reductase (LAR) and anthocyanidin reductase (ANR) were highly expressed at $47 \mathrm{DAA}$ and decreased in the expression at 74. DAA, consistently with the early flavan-3-ols and proanthocyanidin accumulation during berry development [84]. Downregulation of $A N R$ transcript at 47 DAA and upregulation of $L A R$ transcripts at 74 DAA were observed in skins of small compared to large berries indicating a differential regulation of flavan-3-ol biosynthesis during stages that are critical for the accumulation of these compounds and their polymeric forms (proanthocyanidins) in the skin (Fig. 7).

Glycosylation of cyanidin and delphinidin via UDP glucose:flavonoid 3-O-glucosyltransferase (UFGT) [85] is critical in anthocyanin synthesis. The expression of grapevine UFGT (VIT_16s0039g02230) was significantly downregulated at 121 DAA (Cluster 1). MYBA1 and MYBA2 TFs redundantly regulates UFGT expression and modulates anthocyanin accumulation [86-88]. The MYBA transcripts were specifically activated at 74 DAA and decreases approaching 121 DAA (Fig. 7, Additional file 1: Table S5). MYBA1 (VIT_02s0033g00410) was significantly downregulated in small compared to large berries at 74 and $121 \mathrm{DAA}$, while the others $M Y B A$ s were all downregulated at 121 DAA. The observed downregulation of grapevine $M Y B A 1$ in small compared to large berries at 74 DAA is consistent with the lag of anthocyanin accumulation in smaller berries suggesting a delayed onset of ripening. Although no concurrent downregulation of UFGT with MYBA1 was observed in small compared to large berries at 74 DAA, significant reduction of anthocyanin in small berries at 74 DAA might be strongly related to altered regulation of anthocyanin modification and transport pathways regulated by MYBA TFs [88]. Concurrent downregulation of $M Y B A 1$, $M Y B A 2$, and $M Y B A 3$ with many flavonoid pathways transcripts (three $C H S$, seven $F 3^{\prime} 5^{\prime} H$, and UFGT transcripts) targeted by MYBAs [88] did not significantly reduce the concentration of anthocyanin in the skin at 121 DAA. Anthocyanin accumulation ceased from 103 DAA in both small and large berries. This indicates that the precursors for anthocyanin production (e.g. coumaroylCoA) are channeled to the production of other phenolic compounds, such as stilbenes, at late stages of ripening [89].

A marked upregulation of genes encoding enzymes involved in the general phenylpropanoid and stilbenoid pathway, namely phenylalanine ammonia lyase (PAL), cinnamic acid 4-hydroxylase $(\mathrm{C} 4 \mathrm{H})$, 4-coumarate:CoA ligase (4CL), and stilbene synthase (STS), was observed at 47 and 121 DAA (Fig. 7, Additional file 1: Table S5). Of particular interests are transcripts encoding STS enzymes. In plants producing stilbenes, STS catalyzes the production of cis- or trans-resveratrol using 4coumaroyl-CoA and three molecules of malonyl-CoA. Interestingly, trends in gene expression of the majority of transcripts encoding STS and PAL were very similar (Additional file 1: Table S5). Several studies have 
reported that multiple STSs are responsible for the production of stilbene/resveratrol accumulation in the skin during berry development and in response to abiotic and biotic stress [89-91]. A large proportion of PAL and STS transcripts were significantly upregulated in small berries especially at 47 and 121 DAA (Fig. 7). Similar to that of anthocyanin, stilbenes largely accumulate at the onset of ripening [89-91]. However, no DE expression was observed at 74 DAA where their expression tends to peak. Concerted downregulation of $C H S$ and upregulation of STS at 121 DAA in small compared to large berries might relieve the competition for coumaroyl-CoA and malonyl-CoA substrates by CHS; thereby favoring the flux to stilbene production, since anthocyanin levels have plateaued in both berries from 103 DAA onwards (Fig. 3d). Although the higher skin to berry weight ratio often determines a higher concentration of the anthocyanin and stilbenes accumulated in the skin $[2,3]$, concerted upregulation of the stilbene branch in small berries may enhance stilbene levels in wines made from small berries compared to normal and large sized berries harvested at the same time [24]. This induction of $P A L$ and STS genes in small compared to large berries at 121 DAA might also be a consequence of altered hormone levels. Hormones such as ethylene and jasmonic acids are not only involved in the induction of key stilbene genes (STS) and levels in grapevines [92-94] but also, in the case of ethylene, might take part to the over ripening process [28].

Two grapevine MYB TFs, MYB14 (VIT_07s0005g03340) and MYB15 (VIT_05s0049g01020) directly regulate the biosynthesis of stilbene in grapevines [90]. In this study, MYB15 had consistent expression trends, in both small and large berries, peaking at 74 DAA, while MYB14 transcript evolution was not consistent between small and large berries. In large berries, MYB14 transcripts progressively increase until 103 DAA before decreasing at 121 DAA; while, in small berries, MYB14 expression peaked at 47 DAA before decreasing slightly at 74 DAA and increasing again later during ripening (Additional file 1: Table S5). Nonetheless, grapevine MYB14 and MYB15 were significantly upregulated in small berries at 121 and 47 DAA, respectively (Fig. 7). This result indicates their role in the regulation of STS expression and stilbene production in the skin.

\section{Modulation of fatty acid degradation pathways in small and large berries}

Aromatic alcohols and aldehydes derived from the fatty acid metabolism pathways (Fig. 8a), such as hexanol/hexenol and heptanal/hexanal, also contribute to late-ripening associated flavor/aromas in fruits and finished wines [95]. Several successive steps involving lipoxygenase (LOX), hydroperoxide lyase (HPL), alcohol dehydrogenases (ADHs), and alcohol acyl transferases (AATs) enzymes regulate the production of these compounds in plant tissues [96]. Many transcripts encoding enzymes of the aforementioned steps were modulated during fruit development and differed in the abundance between small and large berries (Fig. 8b and c, Additional file 1: Table S5). Lipoxygenase enzymes are involved in the formation of hydroperoxides from linolenic acid, which can lead to the accumulation of key wine aromas in the grape. Two LOX genes differentially expressed between small and large berries were highly expressed at 47 and 74 DAA before decreasing towards 121 DAA. One LOX transcript (VIT_05s0020g03170) was significantly downregulated at 74 DAA and another $L O X$ transcript (VIT_09s0002g01080) was significantly upregulated at 47 DAA in small compared to large berries. Hydroperoxides are then converted to $\mathrm{C} 6$ related aldehydes, which often confer grassy-related aromas via HPL. One HPL transcript (VIT_12s0059g01060), mostly accumulated at 47 and 121 DAA, was downregulated in small compared to large berries. Subsequently, ADH converts C6 related aldehydes to $\mathrm{C} 6$ related alcohols, which can be further converted to produce volatile aromas via AATs. Interestingly, all seven $A D H$ transcripts encoded in the grapevine genome were DE. Four $A D H$ transcripts were highly expressed at 47 DAA and sharply decrease from 74 DAA and onwards; one $A D H$ transcript peaked at 74 DAA while another two were highly expressed at 121 DAA (Fig. 8b). The four early developmental related $A D H$ transcripts (VIT_18s0001 g15410, VIT_04s0044g01110, VIT_04s0044g01120, and VIT_04s0044g01130), as well as two (VIT 18s0001g15450 and VIT_14s0068g01760) of the three late-ripening $A D H$ genes, displayed significant upregulation in small compared to large berries at 47 DAA (Fig. 8c). On the contrary, at 121 DAA, one (VIT_18s0001g15450) of the two $A D H \mathrm{~s}$ that are expressed at high levels at this stage was downregulated in small berries. The accumulation profiles of the different aldehydes, alcohols, and esters in Cabernet Sauvignon grapes during berry development and ripening has been reported and their formation is thought to involve a synergy between the biosynthesis and catabolism of various steps [97]. Although the molecular mechanisms are not fully understood, high levels of volatile esters in young berries ( 6 weeks post flowering) and high levels of alcohol compounds accumulated in later stages of berry development (1214 weeks post flowering) are reported [97]. Therefore, the strong upregulation of four early ripening $A D H$ and one LOX transcripts in small compared to large berries might favor a higher production of C6 aldehydes and subsequent turnover/flux to alcohols/esters (for fruitier aromas) during early development (47 DAA) in small compared to large berries. 


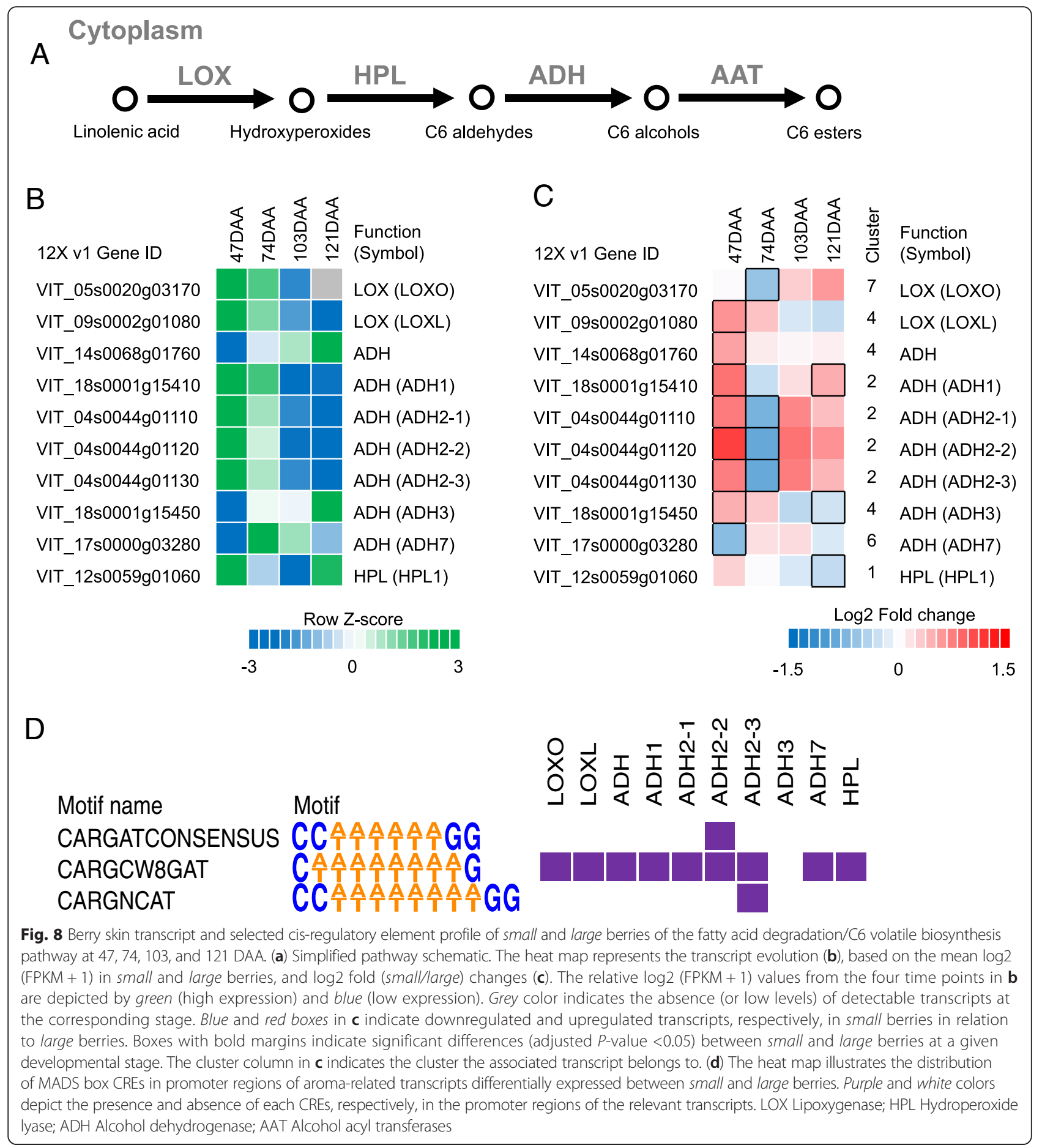

In tomato, a MADS-box transcription factor (SIRIN) is a negative regulator of fruit ripening and acts as a modulator of aroma production in fruits via direct regulation of $A D H, L O X$, and $H P L$ promoters [98]. We identified nine MADS-box TFs differentially expressed between small and large berries: four genes were allocated to clusters 2 , two to clusters 6 , and one to cluster 3,5 , and 7 individually. Of note are the predicted homologs of tomato RIN (VIT_14s0083g01050 and VIT_01s0011g00110), allocated into cluster 2 , that share high expression similarity with four $A D H$ transcripts from 47 to 121 DAA in small and large berries (Additional file 1: Table S5). Analysis of the promoter regions of the total DE 
fatty acid degradation pathway genes (two $L O X$, seven $A D H \mathrm{~s}$, and one $H P L$ ) for various MADS-box binding site (CArG box) revealed that one motif (CWWWWWWWWG) was located within all tested promoter regions except promoter region of an $A D H$ transcript (Fig. 8d, Additional file 1: Table S4). These observations indicate that berry size may be associated with a different accumulation of aromatics in the fruit, likely through the coordinate regulation of MADS-box TFs and structural genes of the fatty acid degradation pathway.

\section{Conclusions}

Significant differences in the physiology, biochemistry, and transcripts are found in different sized berries during fruit development. As small and large berries approach the onset of ripening, clear differences in the rate of development were apparent. Around the onset of ripening, the steeper drop in elasticity, more rapid accumulation of sugars, lower tartaric acid, and greater anthocyanin levels in large compared to small berries suggest that fruit size is associated to changes in the ripening physiology of the berry, where large berries approach ripening faster. These differences correspond to congruent changes in the hormonal pathways related to ABA, auxin, and ethylene via genes encoding NCED for ABA, TAA1/TAR and YUC for auxin, and ACO for ethylene. Genes encoding pathways contributing to fruit texture, flavor, and aroma were also differentially modulated accordingly to the berry size. The modulation of cell wall degradation and modification genes (e.g. PG and EXP) may contribute to the differences in elasticity decreases and berry growth/size. Upregulation of fatty acid degradation genes, especially $A D H$, during early development might favor production of desirable aromatics in small berries. In the late ripening stages, concurrent upregulation of phenylpropanoid and stilbenoid pathway genes with a parallel downregulation of the flavonoid pathway in skins of small compared to large berries indicates that smaller berries may have higher concentrations of aromatics and stilbenes, major antioxidants produced in the berry. Further investigation on endogenous and exogenous factors that regulate the fruit metabolism in berries of different sizes is necessary to identify the key factors - e.g. hormone signals, advantage of position within a cluster that favors mineral or water uptake, or a better microclimate - that determine the berry size itself as well as the transcriptome response. Finally, a deeper investigation of the fruit composition in relation to berry size may lead to the adoption of screening strategies based on size for tailoring fruit and wine quality.

\section{Additional file}

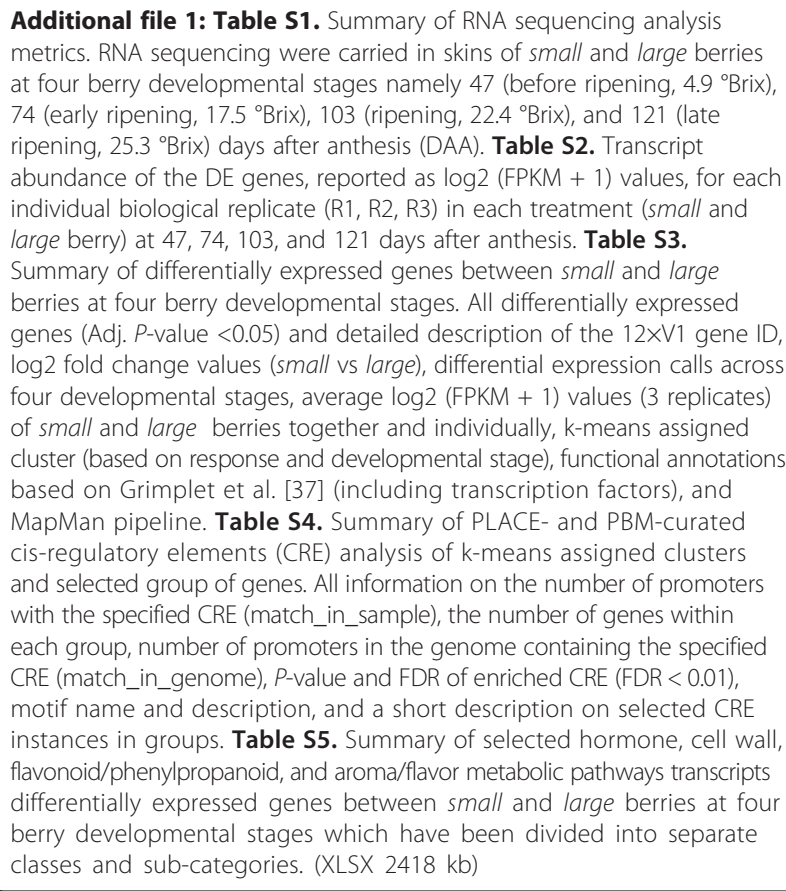

Acknowledgments

We thank Mission Hill Family Estate for providing the grapes used in this study. We thank Dr. Patricia Bowen (Agriculture and Agri-Food Canada) for providing laboratory space during the sample collection. We thank Canada's Michael Smith Genome Sciences Centre for the sequencing services.

\section{Funding}

This study was funded by the University of British Columbia, Genome BC, and Natural Sciences and Engineering Research Council of Canada.

\section{Availability of data and materials}

All raw sequence reads have been deposited in NCBI Sequence Read Archive (http://www.ncbi.nlm.nih.gov/sra). The BioProject and SRA accessions are PRJNA316157 and SRP072255, respectively.

\section{Authors' contributions}

DCJW performed the physiological measurements, liquid chromatography (LC) and LC-mass spectrophotometric analysis, RNA extractions, transcriptome data analysis, cis-regulatory sequence analysis, interpreted the results, and drafted the manuscript. RLG performed the transcriptome and cis-regulatory sequence data analysis. ND performed part of the physiological measurements. GAG contributed to the experimental design, expert advice throughout the study, interpreted the results, and drafted part of the manuscript. SDC conceived the study, coordinated the field experiments, performed the physiological measurements, supervised the entire study, interpreted the results, and drafted part of the manuscript. All authors read and approved the final manuscript.

\section{Competing interests}

The authors declare that they have no competing interests.

\section{Author details}

${ }^{1}$ Wine Research Centre, University of British Columbia, Vancouver, BC, Canada. ${ }^{2}$ Bordeaux Sciences Agro, Institut des Sciences de la Vigne et du Vin, Ecophysiologie et Génomique Fonctionnelle de la Vigne, UMR 1287, F-33140 Villenave d' Ornon, France.

Received: 4 February 2016 Accepted: 25 April 2016

Published online: 31 May 2016 


\section{References}

1. Lund ST, Bohlmann J. The molecular basis for wine grape quality-a volatile subject. Science. 2006;311:804-5.

2. $\quad$ Singleton VL. Effects on red wine quality of removing juice before fermentation to simulate variation in berry size. Am J Enol Vitic. 1972:23:106-13.

3. Matthews MA, Anderson MM. Fruit ripening in Vitis vinifera L.: responses to seasonal water deficits. Am J Enol Vitic. 1988;39:313-20.

4. Coombe BG. Research on development and ripening of the grape berry. Am J Enol Vitic. 1992:43:101-10.

5. Kuhn N, Guan L, Dai ZW, Wu BH, Lauvergeat V, Gomès E, Li SH, Godoy F, Arce-Johnson P, Delrot S. Berry ripening: recently heard through the grapevine. J Exp Bot. 2014;65:4543-59.

6. Böttcher C, Harvey K, Forde CG, Boss PK, Davies C. Auxin treatment of pre-veraison grape (Vitis vinifera L.) berries both delays ripening and increases the synchronicity of sugar accumulation. Aust J Grape Wine Res. 2011;17:1-8.

7. Böttcher C, Burbidge CA, Boss PK, Davies C. Interactions between ethylene and auxin are crucial to the control of grape (Vitis vinifera L.) berry ripening. BMC Plant Biol. 2013;13:222.

8. Chervin C, El-Kereamy A, Roustan JP, Latché A, Lamon J, Bouzayen M. Ethylene seems required for the berry development and ripening in grape, a non-climacteric fruit. Plant Sci. 2004;167:1301-5.

9. Sun L, Zhang M, Ren J, Qi J, Zhang G, Leng P. Reciprocity between abscisic acid and ethylene at the onset of berry ripening and after harvest. BMC Plant Biol. 2010;10:257.

10. Owen SJ, Lafond MD, Bowen P, Bogdanoff C, Usher K, Abrams SR. Profiles of abscisic acid and its catabolites in developing Merlot grape (Vitis vinifera) berries. Am J Enol Vitic. 2009;60:277-84

11. Wheeler S, Loveys B, Ford C, Davies C. The relationship between the expression of abscisic acid biosynthesis genes, accumulation of abscisic acid and the promotion of Vitis vinifera L. berry ripening by abscisic acid. Aust J Grape Wine Res. 2009:15:195-204.

12. Deluc LG, Quilici DR, Decendit A, Grimplet J, Wheatley MD, Schlauch KA, Mérillon J-M, Cushman JC, Cramer GR. Water deficit alters differentially metabolic pathways affecting important flavor and quality traits in grape berries of Cabernet Sauvignon and Chardonnay. BMC Genomics. 2009;10:212

13. Castellarin SD, Gambetta GA, Wada H, Krasnow MN, Cramer GR, Peterlunger E, Shackel KA, Matthews MA. Characterization of major ripening events during softening in grape: turgor, sugar accumulation, abscisic acid metabolism, colour development, and their relationship with growth. J Exp Bot. 2015;67:709-22

14. Scienza A, Miravalle R, Visai C, Fregoni M. Relationships between seed number, gibberellin and abscisic acid levels and ripening in Cabernet Sauvignon grape berries. Vitis 1978;17:361-8

15. Roby G, Matthews MA. Relative proportions of seed, skin and flesh, in ripe berries from Cabernet Sauvignon grapevines grown in a vineyard either well irrigated or under water deficit. Aust J Grape Wine Res. 2004;10:74-82.

16. Friend AP, Trought MCT, Creasy GL. The influence of seed weight on the development and growth of berries and live green ovaries in vitis vinifera $L$. cvs. pinot noir and cabernet sauvignon. Aust J Grape Wine Res. 2009;15:166-74

17. Gouthu S, Deluc LG. Timing of ripening initiation in grape berries and its relationship to seed content and pericarp auxin levels. BMC Plant Biol. 2015;15:1-16.

18. Kennedy JA, Matthews MA, Waterhouse AL. Effect of maturity and vine water status on grape skin and wine flavonoids. Am J Enol Vitic. 2002;53:268-74.

19. Roby G, Harbertson JF, Adams DA, Matthews MA. Berry size and vine water deficits as factors in winegrape composition: anthocyanins and tannins. Aust J Grape Wine Res. 2004;10:100-7.

20. Holt HE, Francis IL, Field J, Herderich MJ, Iland PG. Relationships between berry size, berry phenolic composition and wine quality scores for Cabernet Sauvignon (Vitis vinifera L.) from different pruning treatments and different vintages. Aust J Grape Wine Res. 2008;14:191-202.

21. Dokoozlian NK, Kliewer WM. Influence of light on grape berry growth and composition varies during fruit development. J Am Soc Hortic Sci. 1996:121:869-74

22. Walker RR, Blackmore DH, Clingeleffer PR, Kerridge GH, Rühl EH, Nicholas PR. Shiraz berry size in relation to seed number and implications for juice and wine composition. Aust J Grape Wine Res. 2005;11:2-8.
23. Šuklje K, Lisjak K, Baša Česnik H, Janeš L, Du Toit W, Coetzee Z, Vanzo A, Deloire A. Classification of grape berries according to diameter and tota soluble solids to study the effect of light and temperature on methoxypyrazine, glutathione, and hydroxycinnamate evolution during ripening of sauvignon blanc (Vitis vinifera L.). J Agric Food Chem. 2012;60:9454-61.

24. Gil M, Pascual O, Gómez-Alonso S, García-Romero E, Hermosín-Gutiérrez I, Zamora F, Canals JM. Influence of berry size on red wine colour and composition. Aust J Grape Wine Res. 2015:n/a-n/a

25. Ali MB, Howard S, Chen S, Wang Y, Yu O, Kovacs LG, Qiu W. Berry skin development in Norton grape: distinct patterns of transcriptional regulation and flavonoid biosynthesis. BMC Plant Biol. 2011;11:7

26. Fasoli M, Dal Santo S, Zenoni S, Tornielli GB, Farina L, Zamboni A, Porceddu A, Venturini L, Bicego M, Murino V, Ferrarini A, Delledonne M, Pezzotti M. The grapevine expression atlas reveals a deep transcriptome shift driving the entire plant into a maturation program. Plant Cell. 2012;24:3489-505.

27. Lijavetzky D, Carbonell-Bejerano P, Grimplet J, Bravo G, Flores P, Fenoll J, Hellín $P$, Oliveros JC, Martínez-Zapater JM. Berry flesh and skin ripening features in Vitis vinifera as assessed by transcriptional profiling. PLoS One. 2012;7.

28. Cramer GR, Ghan $R$, Schlauch KA, Tillett RL, Heymann H, Ferrarini A, Delledonne M, Zenoni S, Fasoli M, Pezzotti M. Transcriptomic analysis of the late stages of grapevine (Vitis vinifera cv. Cabernet Sauvignon) berry ripening reveals significant induction of ethylene signaling and flavor pathways in the skin. BMC Plant Biol. 2014;14:1-21.

29. Grimplet J, Deluc LG, Tillett RL, Wheatley MD, Schlauch KA, Cramer GR Cushman JC. Tissue-specific mRNA expression profiling in grape berry tissues. BMC Genomics. 2007;8:187.

30. Carbonell-Bejerano P, Diago M-P, Martínez-Abaigar J, Martínez-Zapater JM Tardáguila J, Núñez-Olivera E. Solar ultraviolet radiation is necessary to enhance grapevine fruit ripening transcriptional and phenolic responses. BMC Plant Biol. 2014;14:183.

31. Thomas T, Shackel K, Matthews M. Mesocarp cell turgor in Vitis vinifera L. berries throughout development and its relation to firmness, growth, and the onset of ripening. Planta. 2008:228:1067-76.

32. Wada H, Matthews MA, Shackel KA. Seasonal pattern of apoplastic solute accumulation and loss of cell turgor during ripening of Vitis vinifera fruit under field conditions. J Exp Bot. 2009;60:1773-81.

33. Jaillon O, Aury J-M, Noel B, Policriti A, Clepet C, Casagrande A, Choisne N, Aubourg S, Vitulo N, Jubin C, Vezzi A, Legeai F, Hugueney P, Dasilva C, Horner D, Mica E, Jublot D, Poulain J, Bruyère C, Billault A, Segurens B, Gouyvenoux M, Ugarte E, Cattonaro F, Anthouard V, Vico V, Del Fabbro C, Alaux M, Di Gaspero $\mathrm{G}$, Dumas $V$, et al. The grapevine genome sequence suggests ancestral hexaploidization in major angiosperm phyla. Nature. 2007:449:463-7.

34. Li H, Durbin R. Fast and accurate short read alignment with BurrowsWheeler transform. Bioinformatics. 2009:25:1754-60.

35. Anders S, Pyl PT, Huber W. HTSeq A Python framework to work with highthroughput sequencing data. Bioinformatics. 2014;31:166-9.

36. Robinson MD, McCarthy DJ, Smyth GK. edgeR: a bioconductor package for differential expression analysis of digital gene expression data. Bioinformatics. 2009;26:139-40.

37. Grimplet J, Van Hemert J, Carbonell-Bejerano P, Díaz-Riquelme J, Dickerson J, Fennell A, Pezzotti M, Martínez-Zapater JM. Comparative analysis of grapevine whole-genome gene predictions, functional annotation, categorization and integration of the predicted gene sequences. BMC Res Notes. 2012;5:213.

38. Lohse M, Nagel A, Herter T, May P, Schroda M, Zrenner R, Tohge T, Fernie AR, Stitt M, Usadel B. Mercator: a fast and simple web server for genome scale functional annotation of plant sequence data. Plant Cell Environ. 2014;37:1250-8.

39. Thimm O, Bläsing O, Gibon Y, Nagel A, Meyer S, Krüger P, Selbig J, Müller LA, Rhee SY, Stitt M. MAPMAN: a user-driven tool to display genomics data sets onto diagrams of metabolic pathways and other biological processes. Plant J. 2004;37:914-39.

40. Vitulo N, Forcato C, Carpinelli EC, Telatin A, Campagna D, D'Angelo M Zimbello R, Corso M, Vannozzi A, Bonghi C, Lucchin M, Valle G. A deep survey of alternative splicing in grape reveals changes in the splicing machinery related to tissue, stress condition and genotype. BMC Plant Biol. 2014:14:99.

41. Franco-Zorrilla JM, López-Vidriero I, Carrasco JL, Godoy M, Vera P, Solano R. DNA-binding specificities of plant transcription factors and their potential to define target genes. Proc Natl Acad Sci U S A. 2014;111:2367-72. 
42. Higo K, Ugawa Y, Iwamoto M, Korenaga T. Plant cis-acting regulatory DNA elements (PLACE) database: 1999. Nucleic Acids Res. 1999;27:297-300.

43. Ma S, Shah S, Bohnert HJ, Snyder M, Dinesh-Kumar SP. Incorporating motif analysis into gene co-expression networks reveals novel modular expression pattern and new signaling pathways. PLoS Genet. 2013;9.

44. Sweetman C, Wong DC, Ford CM, Drew DP. Transcriptome analysis at four developmental stages of grape berry (Vitis vinifera cv. Shiraz) provides insights into regulated and coordinated gene expression. BMC Genomics. 2012;13:691.

45. Gambetta GA, Matthews MA, Shaghasi TH, McElrone AJ, Castellarin SD. Sugar and abscisic acid signaling orthologs are activated at the onset of ripening in grape. Planta. 2010;232:219-34

46. Dai Z, Meddar M, Renaud C, Merlin I, Hilbert G, Delro S, Gomès E. Long-term in vitro culture of grape berries and its application to assess the effects of sugar supply on anthocyanin accumulation. J Exp Bot. 2014;65:4665-77.

47. Gouthu S, O'Neil ST, Di Y, Ansarolia M, Megraw M, Deluc LG. A comparative study of ripening among berries of the grape cluster reveals an altered transcriptional programme and enhanced ripening rate in delayed berries. J Exp Bot. 2014;65:5889-5902

48. Karlova R, Chapman N, David K, Angenent GC, Seymour GB, De Maagd RA. Transcriptional control of fleshy fruit development and ripening. J Exp Bot. 2014;65:4527-41.

49. Leng $P$, Yuan $B, G$ Gu $Y$, Chen $P$. The role of abscisic acid in fruit ripening and responses to abiotic stress. J Exp Bot. 2014;65:4577-88.

50. Sun L, Sun Y, Zhang M, Wang L, Ren J, Cui M, Wang Y, Ji K, Li P, Li Q, Chen P, Dai S, Duan C, Wu Y, Leng P. Suppression of 9-cis-epoxycarotenoid dioxygenase, which encodes a key enzyme in abscisic acid biosynthesis, alters fruit texture in transgenic tomato. Plant Physiol. 2012;158:283-98.

51. Böttcher C, Keyzers RA, Boss PK, Davies C. Sequestration of auxin by the indole-3-acetic acid-amido synthetase GH3-1 in grape berry (Vitis vinifera L.) and the proposed role of auxin conjugation during ripening. J Exp Bot. 2010;61:3615-25.

52. Böttcher C, Boss PK, Davies C. Acyl substrate preferences of an IAA-amido synthetase account for variations in grape (Vitis vinifera L.) berry ripening caused by different auxinic compounds indicating the importance of auxin conjugation in plant development. J Exp Bot. 2011;62:4267-80.

53. Böttcher C, Harvey KE, Boss PK, Davies C. Ripening of grape berries can be advanced or delayed by reagents that either reduce or increase ethylene levels. Funct Plant Biol. 2013;40:566-81.

54. Davies C, Nicholson EL, Böttcher C, Burbidge CA, Bastian SEP, Harvey KE, Huang A-C, Taylor DK, Boss PK. Shiraz wines made from grape berries (Vitis vinifera) delayed in ripening by plant growth regulator treatment have elevated rotundone concentrations and "pepper" flavor and aroma. J Agric Food Chem. 2015;63:2137-44.

55. Nicolas P, Lecourieux D, Kappel C, Cluzet S, Cramer G, Delrot S, Lecourieux F. The basic leucine zipper transcription factor ABSCISIC ACID RESPONSE ELEMENT-BINDING FACTOR2 is an important transcriptional regulator of abscisic Acid-dependent grape berry ripening processes. Plant Physiol. 2013;164:365-83.

56. Vicente AR, Saladié M, Rose JK, Labavitch JM. The linkage between cell wall metabolism and fruit softening: looking to the future. J Sci Food Agric. 2007;87:1435-48

57. Matthews MA, Cheng G, Weinbaum SA. Changes in water potential and dermal extensibility during grape berry development. J Am Soc Hortic Sci. 1987:314-9

58. Huang XM, Huang HB, Wang HC. Cell walls of loosening skin in postveraison grape berries lose structural polysaccharides and calcium while accumulate structural proteins. Sci Hortic (Amsterdam). 2005;104:249-63.

59. Schlosser J, Olsson N, Weis M, Reid K, Peng F, Lund S, Bowen P. Cellular expansion and gene expression in the developing grape (Vitis vinifera L.). Protoplasma. 2008;232:255-65.

60. Powell ALT, Kalamaki MS, Kurien PA, Gurrieri S, Bennett AB. Simultaneous transgenic suppression of LePG and LeExp1 influences fruit texture and juice viscosity in a fresh market tomato variety. J Agric Food Chem. 2003;51:7450-5.

61. Atkinson RG, Sutherland PW, Johnston SL, Gunaseelan K, Hallett IC, Mitra D, Brummell DA, Schröder R, Johnston JW, Schaffer RJ. Down-regulation of POLYGALACTURONASE1 alters firmness, tensile strength and water loss in apple (Malus x domestica) fruit. BMC Plant Biol. 2012;12:129.

62. Pose S, Paniagua C, Cifuentes M, Blanco-Portales R, Quesada MA, Mercado JA. Insights into the effects of polygalacturonase FaPG1 gene silencing on pectin matrix disassembly, enhanced tissue integrity, and firmness in ripe strawberry fruits. J Exp Bot. 2013;64:3803-15.

63. Jiménez-Bermúdez S, Redondo-Nevado J, Muñoz-Blanco J, Caballero JL, López-Aranda JM, Valpuesta V, Pliego-Alfaro F, Quesada MA, Mercado JA. Manipulation of strawberry fruit softening by antisense expression of a pectate lyase gene. Plant Physiol. 2002;128:751-9.

64. Santiago-Domenech N, Jimenez-Bemudez S, Matas AJ, Rose JKC, MunozBlanco J, Mercado JA, Quesada MA. Antisense inhibition of a pectate lyase gene supports a role for pectin depolymerization in strawberry fruit softening. J Exp Bot. 2008;59:2769-79.

65. Licausi F, Ohme-Takagi M, Perata P. APETALA2/Ethylene Responsive Factor (AP2/ERF) transcription factors: mediators of stress responses and developmental programs. New Phytol. 2013:639-49

66. Ishimaru M, Smith DL, Gross KC, Kobayashi S. Expression of three expansin genes during development and maturation of Kyoho grape berries. J Plant Physiol. 2007;164:1675-82.

67. Dal Santo S, Vannozzi A, Tornielli GB, Fasoli M, Venturini L, Pezzotti M, Zenoni S. Genome-wide analysis of the expansin gene superfamily reveals grapevine-specific structural and functional characteristics. PLoS One. 2013;8, e62206.

68. Suzuki H, Oshita E, Fujimori N, Nakajima Y, Kawagoe $Y$, Suzuki S. Grape expansins, VVEXPA14 and VVEXPA18 promote cell expansion in transgenic Arabidopsis plant. Plant Cell Tissue Organ Cult. 2014;120:1077-85.

69. Brummell D, Harpster M, Civello P, Palys J, Bennett A, Dunsmuir P. Modification of expansin protein abundance in tomato fruit alters softening and cell wall polymer metabolism during ripening. Plant Cell. 1999;11:2203-16.

70. Wong DCJ, Sweetman C, Drew DP, Ford CM. VTCdb: a gene co-expression database for the crop species Vitis vinifera (grapevine). BMC Genomics. 2013;14:882.

71. Nicolas $P$, Lecourieux D, Gomès E, Delrot $S$, Lecourieux $F$. The grape berryspecific basic helix-loop-helix transcription factor VvCEB1 affects cell size. J Exp Bot. 2013:64:991-1003.

72. Simpson SD, Nakashima K, Narusaka Y, Seki M, Shinozaki K, YamaguchiShinozaki K. Two different novel cis-acting elements of erd1, a clpA homologous Arabidopsis gene function in induction by dehydration stress and dark-induced senescence. Plant J. 2003;33:259-70.

73. Tran LP, Nakashima K, Sakuma Y, Simpson SD, Fujita Y, Maruyama K, Fujita M, Seki M, Shinozaki K, Yamaguchi-Shinozaki K. Isolation and functional analysis of Arabidopsis stress-inducible NAC transcription factors that bind to a drought-responsive cis-element in the early responsive to dehydration stress 1 promoter. Plant Cell. 2004;16:2481-98.

74. Tello J, Torres-Pérez R, Grimplet J, Carbonell-Bejerano P, Martínez-Zapater JM, Ibáñez J. Polymorphisms and minihaplotypes in the VvNAC26 gene associate with berry size variation in grapevine. BMC Plant Biol. 2015;15:253.

75. Vogt T. Phenylpropanoid biosynthesis. Mol Plant. 2010;3:2-20.

76. Castellarin SD, Bavaresco L, Falginella L, Gonçalves MIVZ, Di Gaspero G. Phenolics in grape berry and key antioxidants. In: Gerós H, Chaves MM, Delrot S, editors. The biochemistry of the grape berry. Bentham Science Publishers, Sharjah, U.A.E.2012;89-110.

77. Falginella L, Di Gaspero G, Castellarin SD. Expression of flavonoid genes in the red grape berry of "Alicante Bouschet" varies with the histological distribution of anthocyanins and their chemical composition. Planta. 2012;236:1037-51

78. Falginella L, Castellarin SD, Testolin R, Gambetta GA, Morgante M, Di Gaspero G. Expansion and subfunctionalisation of flavonoid 3',5'hydroxylases in the grapevine lineage. BMC Genomics. 2010;11:562.

79. Castellarin SD, Di Gaspero G, Marconi R, Nonis A, Peterlunger E, Paillard S, Adam-Blondon A-F, Testolin R. Colour variation in red grapevines (Vitis vinifera L.): genomic organisation, expression of flavonoid 3'-hydroxylase, flavonoid 3',5'-hydroxylase genes and related metabolite profiling of red cyanidin-/blue delphinidin-based anthocyanins in berry skin. BMC Genomics. 2006;7:12.

80. Downey MO, Harvey JS, Robinson SP. Synthesis of flavonols and expression of flavonol synthase genes in the developing grape berries of Shiraz and Chardonnay (Vitis vinifera L.). Aust J Grape Wine Res. 2003;9:110-21.

81. Castellarin SD, Pfeiffer A, Sivilotti P, Degan M, Peterlunger E, Di Gaspero G. Transcriptional regulation of anthocyanin biosynthesis in ripening fruits of grapevine under seasonal water deficit. Plant Cell Environ. 2007:30:1381-99.

82. Downey MO, Harvey JS, Robinson SP. The effect of bunch shading on berry development and flavonoid accumulation in Shiraz grapes. Aust J Grape Wine Res. 2004;10:55-73. 
83. Matus JT, Loyola R, Vega A, Pena-Neira A, Bordeu E, Arce-Johnson P, Alcalde JA. Post-veraison sunlight exposure induces MYB-mediated transcriptional regulation of anthocyanin and flavonol synthesis in berry skins of Vitis vinifera. J Exp Bot. 2009:60:853-67.

84. Bogs J, Downey MO, Harvey JS, Ashton AR, Tanner GJ, Robinson SP. Proanthocyanidin synthesis and expression of genes encoding leucoanthocyanidin reductase and anthocyanidin reductase in developing grape berries and grapevine leaves. Plant Physiol. 2005;139:652-63.

85. Ford CM, Boss PK, Hæj PB. Cloning and characterization of Vitis vinifera UDP-glucose. Flavonoid 3- O-Glucosyltransferase, a homologue of the enzyme encoded by the maize Bronze- 1 locus that may primarily serve to glucosylate anthocyanidins in vivo. J Biol Chem. 1998;273:9224-33.

86. Kobayashi S, Ishimaru M, Hiraoka K, Honda C. Myb-related genes of the Kyoho grape (Vitis labruscana) regulate anthocyanin biosynthesis. Planta. 2002:215:924-33.

87. Cutanda-Perez M-C, Ageorges A, Gomez C, Vialet S, Terrier N, Romieu C, Torregrosa L. Ectopic expression of VImybA1 in grapevine activates a narrow set of genes involved in anthocyanin synthesis and transport. Plant Mol Biol. 2009;69:633-48.

88. Rinaldo A, Cavallini E, Jia Y, Moss SMA, McDavid DAJ, Hooper LC, Robinson SP, Tornielli GB, Zenoni S, Ford CM, Boss PK, Walker AR. A grapevine anthocyanin acyltransferase, transcriptionally regulated by VvMYBA, can produce most acylated anthocyanins present in grape skins. Plant Physiol. 2015;169(November):01255.2015.

89. Gatto P, Vrhovsek U, Muth J, Segala C, Romualdi C, Fontana P, Pruefer D, Stefanini M, Moser C, Mattivi F, Velasco R. Ripening and genotype control stilbene accumulation in healthy grapes. J Agric Food Chem. 2008;56:11773-85.

90. Höll J, Vannozzi A, Czemmel S, D'Onofrio C, Walker AR, Rausch T, Lucchin M, Boss PK, Dry IB, Bogs J. The R2R3-MYB transcription factors MYB14 and MYB15 regulate stilbene biosynthesis in Vitis vinifera. Plant Cell. 2013;25:4135-49.

91. Deluc LG, Decendit A, Papastamoulis Y, Mérillon JM, Cushman JC, Cramer GR. Water deficit increases stilbene metabolism in cabernet sauvignon berries. J Agric Food Chem. 2011:59:289-97.

92. Vezzulli S, Civardi S, Ferrari F, Bavaresco L. Methyl jasmonate treatment as a trigger of resveratrol synthesis in cultivated grapevine. Am J Enol Vitic 2007:58:530-3.

93. Belhadj A, Telef N, Cluzet S, Bouscaut J, Corio-Costet MF, Mérillon JM. Ethephon elicits protection against Erysiphe necator in grapevine. J Agric Food Chem. 2008:56:5781-7.

94. D'Onofrio C, Cox A, Davies C, Boss PK. Induction of secondary metabolism in grape cell cultures by jasmonates. Funct Plant Biol. 2009;36:323-38.

95. Ebeler SE, Thorngate JH. Wine chemistry and flavor: Looking into the crystal glass. J Agric Food Chem. 2009;57:8098-108.

96. Feussner I, Wasternack C. The lipoxygenase pathway. Annu Rev Plant Biol. 2002;53:275-97.

97. Kalua CM, Boss PK. Evolution of volatile compounds during the development of cabernet sauvignon grapes (vitis vinifera I.). J Agric Food Chem. 2009:57:3818-30.

98. Qin G, Wang Y, Cao B, Wang W, Tian S. Unraveling the regulatory network of the MADS box transcription factor RIN in fruit ripening. Plant J. 2012;70:243-55.

\section{Submit your next manuscript to BioMed Central and we will help you at every step:}

- We accept pre-submission inquiries

- Our selector tool helps you to find the most relevant journal

- We provide round the clock customer support

- Convenient online submission

- Thorough peer review

- Inclusion in PubMed and all major indexing services

- Maximum visibility for your research

Submit your manuscript at www.biomedcentral.com/submit

) Biomed Central 